\title{
African solutions to African problems? \\ The African Union's sanctions regime regarding unconstitutional changes of government
}

\author{
by \\ Cynthia Mouafo Piaplie
}

A thesis submitted to the Faculty of Graduate and Postdoctoral Affairs in partial fulfillment of the requirements for the degree of

Master of Arts

in

International Affairs

Carleton University

Ottawa, Ontario

(C) 2019, Cynthia Mouafo Piaplie 


\begin{abstract}
Unconstitutional changes of government (UCG) remain a constant challenge to democracy, governance and political stability on the African continent. These occurrences in the post-Cold War era have been characterized by the emergence of more subtle ways of accessing and maintaining power. To respond to the threat, the African Union (AU), supported by sub-regional entities, has adopted a zero-tolerance policy against UCGs. Such response includes the establishment of a sanctions regime to ensure a return to democratic and constitutional order in case of UCG in a given member state. Despite significant normative and practical gaps, the AU norm on UCG shows promise and remains a valuable tool to address anti-democratic coups on the continent. Moving forward, it is imperative to focus on improving the current legal and institutional framework against UCG to foster a more comprehensive and coordinated African-led response to these crises on the continent.
\end{abstract}




\section{Acknowledgements}

I want to thank my supervisor, Dr. Fen Hampson, for guiding me through this dissertation with prowess, confidence and grace. Many thanks to my advisor, Dr. Kamari Clarke, for her precious time and much-needed counsel.

I owe my profound appreciation to Dr. Paul Mkandawire and Dr. Andrea Charron for shaping this thesis into what it is today.

On a more personal note, I would like to thank my father for the sacrifices he has made and which have led me to this accomplishment, and for teaching me the importance of hard work and dedication.

My unconditional love goes to my mother, my sweet guardian angel, for being the better part of me and for symbolizing all that is strong, brave and beautiful. You are with me in all moments.

Special thanks are given to my big sister who's always looked out for me and whose resilience has been both a motivation and a reminder. Thank you to my friends and family for their unwavering encouragement and patience.

Last but not least, I wish to express my deepest gratitude to my love, Philippe, who has been my root, relief and rock from beginning to end. Your unswerving faith and support have gotten me through it all. 


\section{Table of Contents}

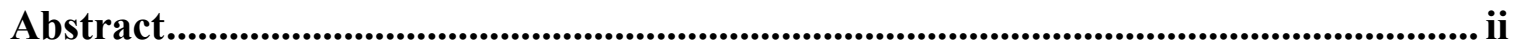

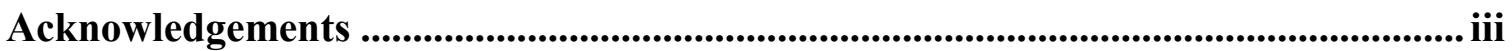

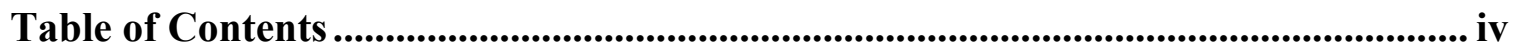

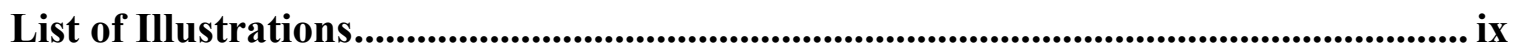

List of Appendices................................................................................................................... $\mathrm{x}$

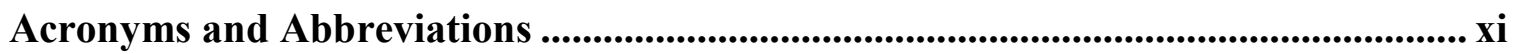

Chapter 1: Introduction .................................................................................................................. 1

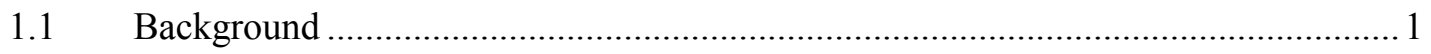

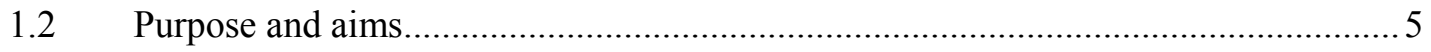

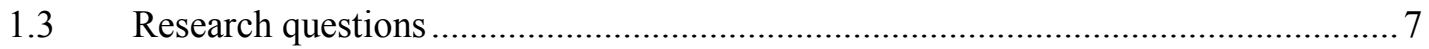

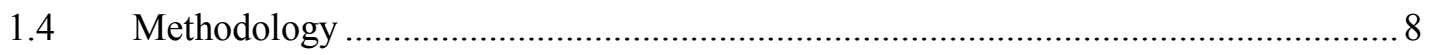

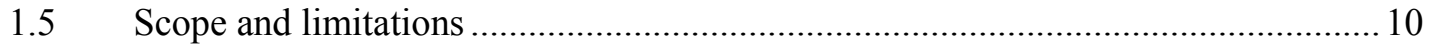

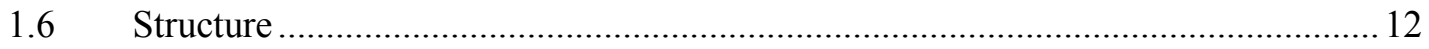

Chapter 2: Sanctions................................................................................................................... 14

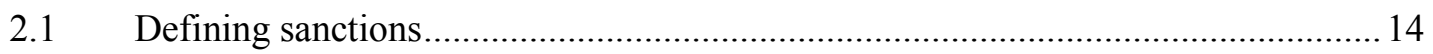

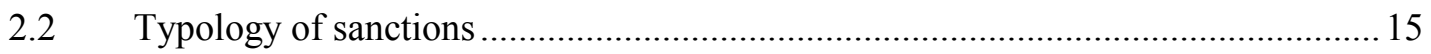

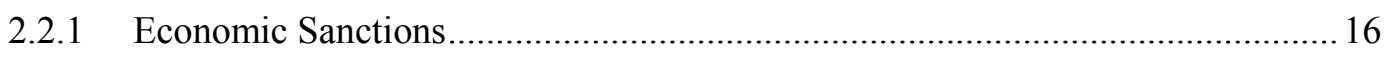

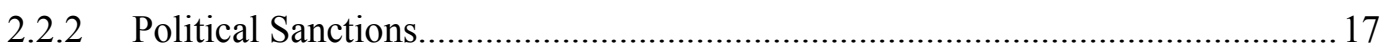

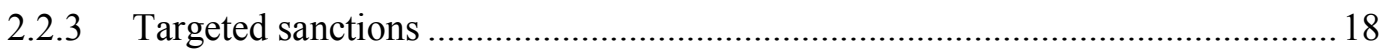

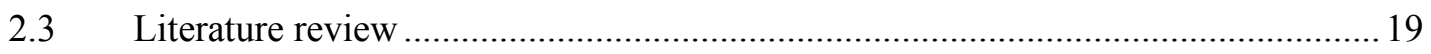

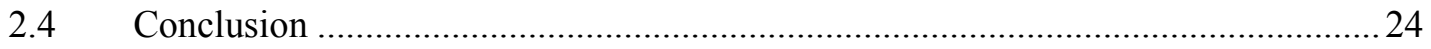

Chapter 3: The African Union........................................................................................... 25

3.1 Establishment of the African Unity: the Organization of African Unity .................25

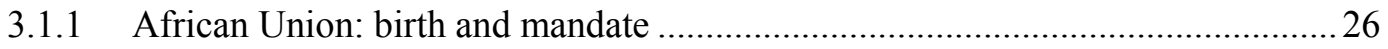




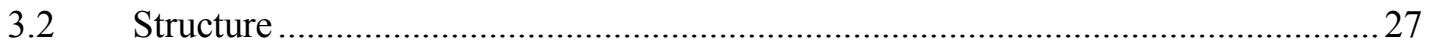

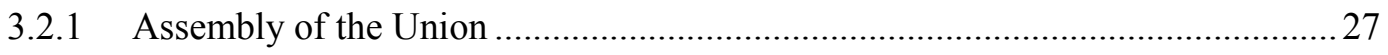

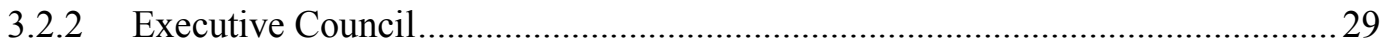

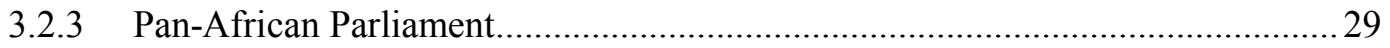

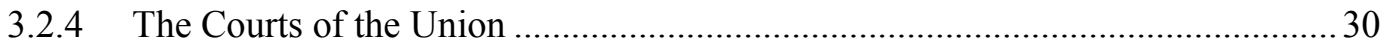

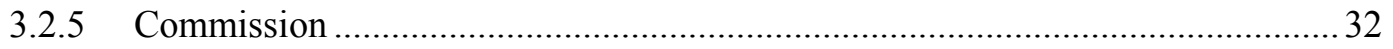

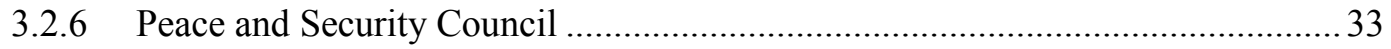

3.2.7 Other Organs: Permanent Representative Committee, Specialized Technical

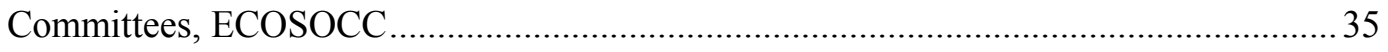

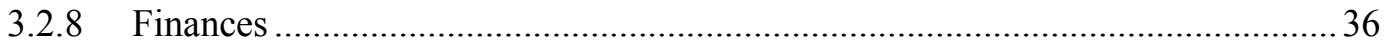

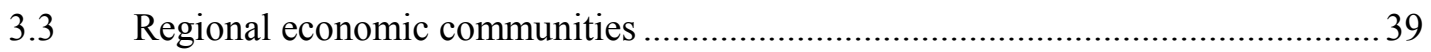

3.3.1 Economic Community of West African States (ECOWAS) .............................. 40

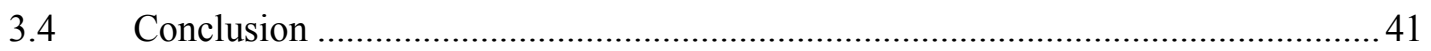

Chapter 4: Responding to UCGs in Africa through sanctions ................................ 43

4.1 Defining unconstitutional changes of government within the AU framework ........ 43

4.1.1 Classification of unconstitutional changes of government .................................45

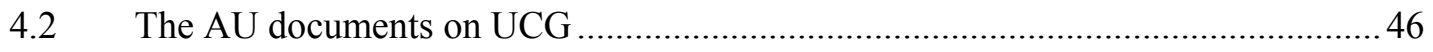

4.2.1 The Lomé Declaration on the Framework for an OAU Response to

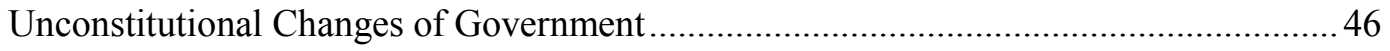

4.2.2 The Constitutive Act of the African Union....................................................... 47

4.2.3 The African Charter on Democracy, Elections and Governance .........................48

4.2.4 The Ezulwini Framework for the Enhancement of the Implementation of Measures of the African Union in Situations of Unconstitutional Changes of Government

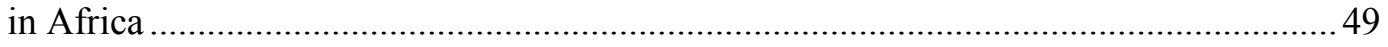

4.3 The African Peace and Security Architecture ..................................................... 49

4.3.1 The Peace and Security Council ................................................................... 51 


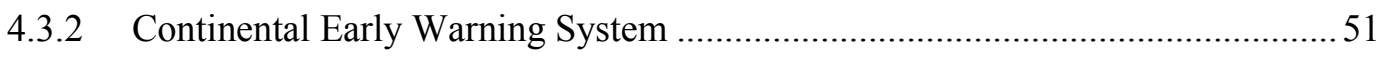

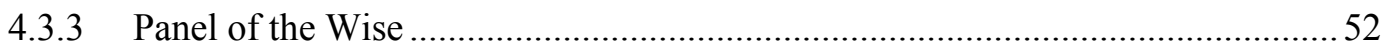

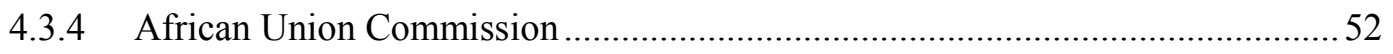

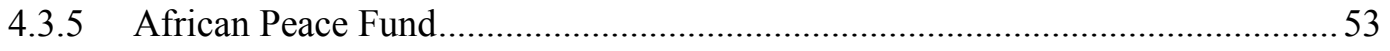

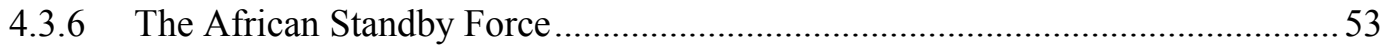

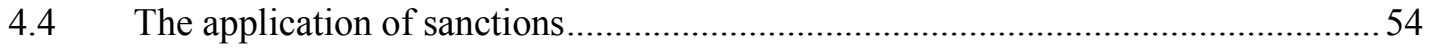

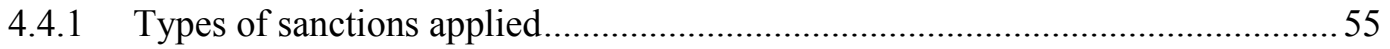

4.4.2 Sanctions' application in practice: successes and failures .................................55

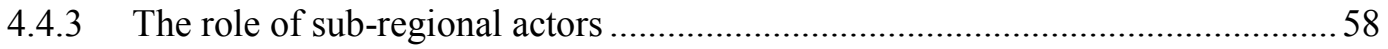

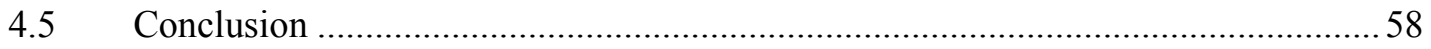

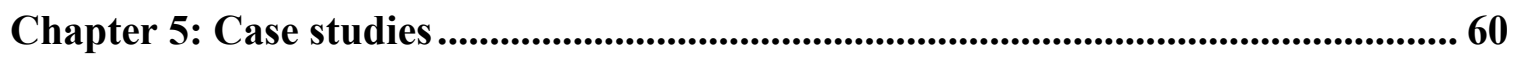

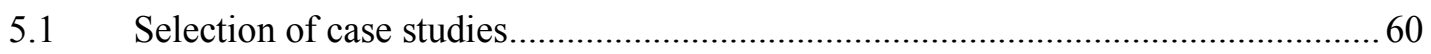

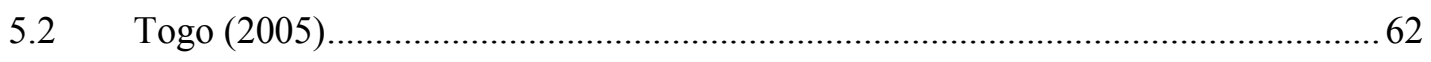

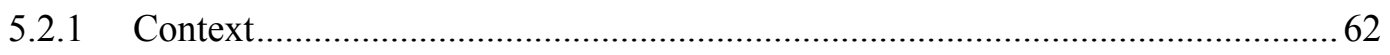

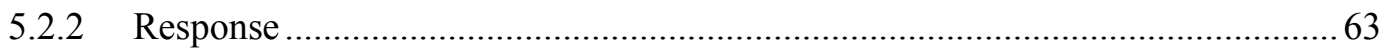

5.2.3 Outcome

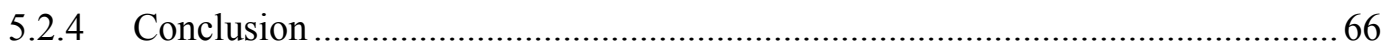

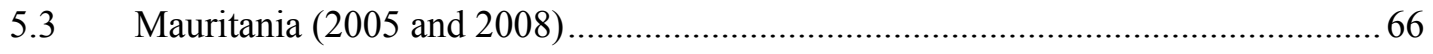

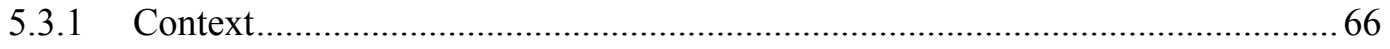

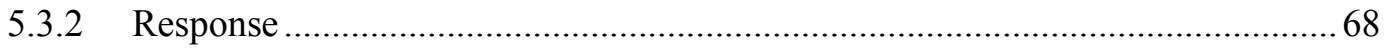

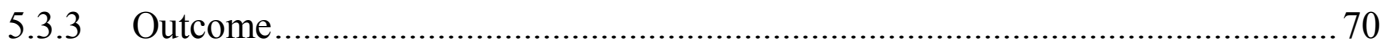

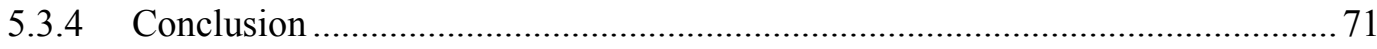

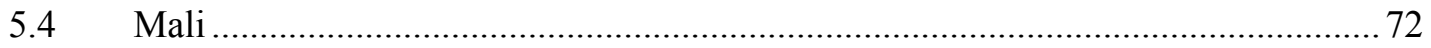

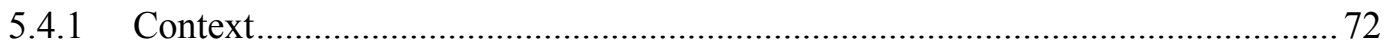

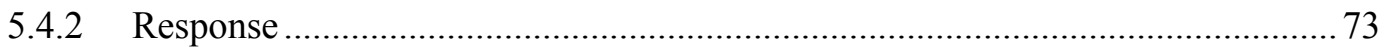

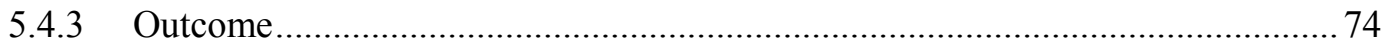




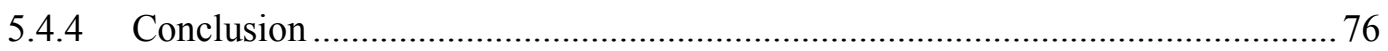

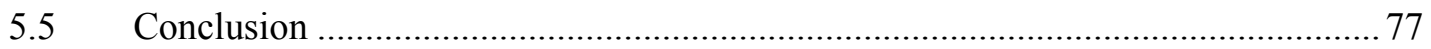

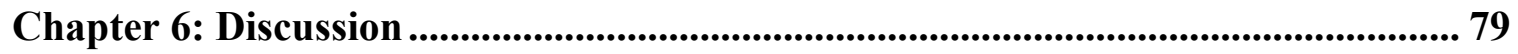

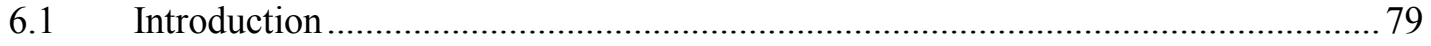

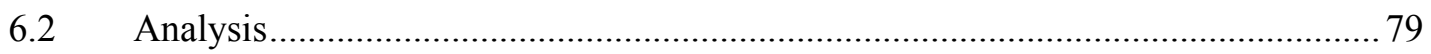

6.2.1 Togo, Mauritania and Mali: comparing three cases of UCGs in West Africa..... 79

6.2.2 A post-2002 shift in the AU's sanctions regime against UCGs? ........................84

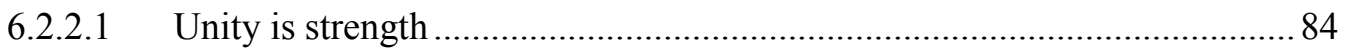

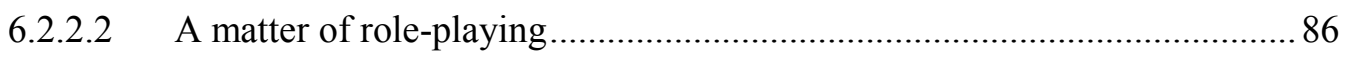

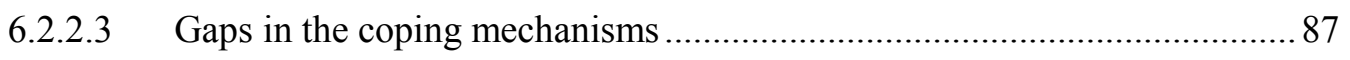

6.3 What about "good" coups d'état? The Zimbabwean case.......................................90

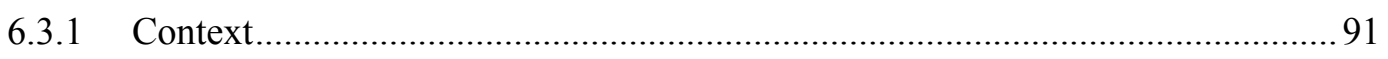

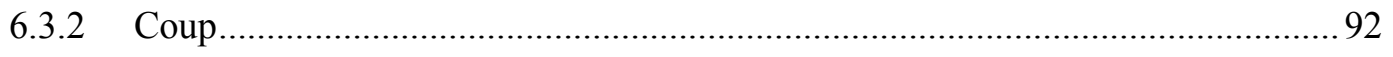

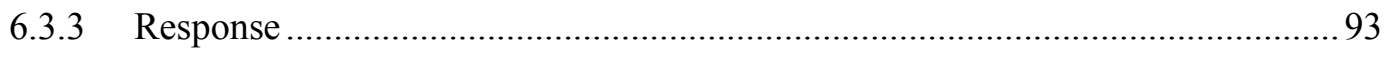

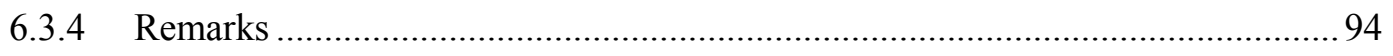

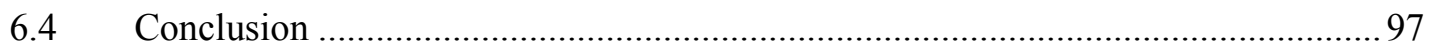

Chapter 7: Conclusion ............................................................................................. 99

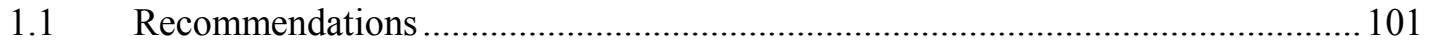

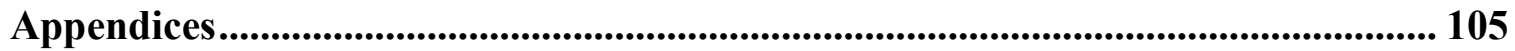

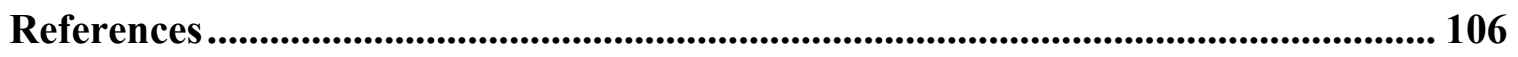




\section{List of Tables}

Table 1 Cases of UCG resulting in sanctions application by the African Union .......... 56 


\section{List of Illustrations}

Illustration 1 Gap between the planned Commission budget and actual budget that is funded by both member states and Partners: 2011-2015 .......................................... 38

Illustration 2 Pillars of the African Peace and Security Architecture ........................... 51 


\section{List of Appendices}

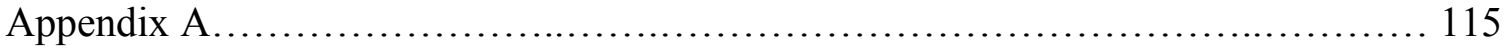

A.1 Number of Military Coups (successful and attempted per Sub-region).........115 


\section{Acronyms and Abbreviations}

\begin{tabular}{|c|c|}
\hline $\mathrm{ACB}$ & African Central Bank \\
\hline ACEG & African Charter on Democracy, Elections and Governance \\
\hline AHSG & Assembly of Heads of State and Government \\
\hline AIB & African Investment Bank \\
\hline AMU & Arab Maghreb Union \\
\hline $\mathrm{AMF}$ & African Monetary Fund \\
\hline APSA & African Peace and Security Architecture \\
\hline AU & African Union \\
\hline CADSP & Common African Defence and Security Policy \\
\hline CEN-SAD & Economic Community of Sahelo-Saharian States \\
\hline CEWS & Continental Early Warning System \\
\hline COMESA & Common Market of East and Southern Africa \\
\hline EAC & the East African Community \\
\hline ECCAS & Economic Community of Central African States \\
\hline ECOSOCC & Economic, Social and Cultural Council \\
\hline ECOWAS & Economic Community for West African States \\
\hline EU & European Union \\
\hline IGAD & Inter-Governmental Authority for Development \\
\hline NEPAD & New Partnership for Africa's Development \\
\hline OAU & Organization of African Unity \\
\hline PSC & African Union Peace and Security Council \\
\hline SADC & Southern African Development Community \\
\hline
\end{tabular}


UCG Unconstitutional Change of Government

UN United Nations

UNSC United Nations Security Council

ZANU-PF Zimbabwe African National Union-Patriotic Front 


\section{Chapter 1: Introduction}

This chapter serves as an introduction for this dissertation. It comprises six sections: the first section offers the background leading to this study; the second states its purpose and aims; the third describes the research questions; the fourth focuses on the methodology, while the fifth addresses the scope and limitations of the dissertation. Finally, the sixth section presents the structure of the study.

\subsection{Background}

Since 1960, the African continent has witnessed more than 200 military coups, whether successful or aborted (Barka \& Ncube, 2012, p. 1). Until the end of the Cold War, military coups constituted the most common form of unconstitutional changes of government, causing serious setbacks to the democratic process initiated after the independence. The trend somewhat changed in the 1990s onward as states embraced the democratic way of accession to power through elections. This new trend, however, did not completely end the practice of military coups d'état, as many countries experienced them until as recently as 2018. In addition, "a new trend of subtle unconstitutional change of government is taking place on the continent: the practice of amending constitutions or other electoral laws in order for incumbent to remain in power for additional terms or for life" (Manirakiza, 2016, p. 87). This new category of soft UCGs raises a number of additional legal challenges compared to the classical type of UCGs which involved mainly the use of or the threat to use force to overthrow a legitimate government. 
Recognizing the challenge unconstitutional changes of government present to democracy and political stability, the African Union is generally opposed to coups and the practice of amending constitutions to extent or remove limits on tenure of office. Formed in 1963, the African Union (AU), then known as the Organization of African Unity (OAU), was created to address adverse political and economic conditions prevailing in different African countries, as well as fend off foreign influence at work during different periods (post-independence, Cold War and post-Cold War eras). Following the end of the Cold War, the OAU had to reconsider its role in Africa's development. As a result, the African Union was established in 2000 to address the new social, political and economic realities on the continent. In addition to addressing some of the structural and practical weaknesses of the OAU, the African Union's mandate is more proactive than that of its predecessor with regards to intervention in internal conflicts. The organization also places further emphasis on the promotion of good governance by explicitly condemning and rejecting unconstitutional changes of government (UCG), as prescribed by Article 4 of the Constitutive Act of the African Union.

Within the African Union, UCGs have been linked to political instability, deficit in democracy and bad governance ${ }^{1}$ because inherent weaknesses in African countries' institutions "tend to undermine their capability to formulate, regulate, and ensure

\footnotetext{
${ }^{1}$ Decision on the Resurgence of the Scourge of Coups d'État in Africa, Assembly/AU/Dec.220(XII), para.1. For the AU Assembly of Heads of State and Government, an unconstitutional change of government "(...) undermines the progress achieved in the ongoing democratization processes in the Continent and constitutes a threat to peace and security in Africa", see Decision on the Prevention of Unconstitutional Changes of Government and Strengthening the Capacity of the African Union to Manage Such Situations, Doc. Assembly/AU/4(XVI), Assembly/AU/Dec.269(XIV) Rev.1, para. 3.
} 
enforcement of democratic norms and practices in manners that will foster socioeconomic transformation and political development" (Centre for Democracy and Development $[\mathrm{CDD}])$. This finding prompted the organization to adopt, in 2009, a number of legal and policy instruments outlawing anti-democratic practices of accession to power.

The re-emerging pattern of military coups and other forms of governance-related issues which have hit the African continent in recent years happens at a time where the AU is striving to calibrate its mechanisms and relevant policy/legal instruments to address what has been deemed one of the major sources of dysfunctionality in the postcolonial African state.

Through these instruments, the organization seeks to assert its adoption of a zerotolerance policy for coups and other violations of democratic order. This policy is done in practice through public condemnation of the UCG and a call for the speedy return to constitutional order. In addition, the unconstitutional regime is suspended from all AU decision-making organs and is given a period of up to six months to restore constitutional order. At the end of the six-month period, the AU may then impose a range of targeted sanctions to ensure a return to democratic and constitutional order in the member state.

Concomitantly, a number of aspects bring questions to the implementation of the policy. For one, the organization does not have a mechanism in place to challenge leaders that came into power before the framework existed. At times, it even appears to reward such leaders, as was the case with Libya's Muammar Qaddafi who was named Chairman of the AU between 2000 and 2005, and again in 2009-2010, despite coming to power in a military coup in 1980. The partiality of the African Union's Peace Security Council 
(PSC) in imposing sanctions, the weakness of the Continental Early Warning System (CEWS) and the absence of cohesive measures are other problems identified by scholars and members of civil society in the AU's response to UCG. Moreover, when it comes to UCG, cases that the AU has not taken up are as significant as those that have elicited a response. These paradoxes between the theoretical and practical assertions of the AU speaks to the organization's limitations in implementing its framework on UCG. There is however no doubt that in evolving its response to UCG, the AU has demonstrated proactiveness and preparedness to address these situations. By adopting their zero-tolerance regarding UCG, "African leaders [...] have achieved the firm establishment of a strong culture of intolerance towards coups" (Dube, 2010, p. 36). This initiative is a sign of maturity on the part of the $\mathrm{AU}$ and has proven to be beneficial on numerous occasions.

In fact, following the AU's adoption of the policy and legal framework against UCGs, there was a substantial decrease in the number of successful undemocratic changes, although the phenomenon did not end. Yet, through its swift and firm intervention in sovereignty-related issues of this nature, the organization has asserted its authority and influence on the continent (Manirakiza, 2016, p. 105). Today, sanctions remain the most far reaching measure in the AU framework of response against UCG, and theoretically the UCG framework of the AU reflects its commitment to ensuring democratic governance. However, both successes and failures characterize the AU in its quest to fulfill its mandate. 


\subsection{Purpose and aims}

This study examines some of the international community's skepticism regarding sanctions as an effective tool of peace and security maintenance by looking at the African Union's sanctions regime as a response to unconstitutional changes of government. The AU has adopted a zero-tolerance policy on UCG, comprised of a sanctions regime, which refuses to recognize regimes that come to power through coups. In many instances, this policy has resulted in the restoration of democratic and constitutional order. Yet, simultaneously, the practice of the AU has been selective, with the organization often showing indifference to how the governments of its member states came to power prior to the existence of the UCG framework. The objectivity of the PSC is further questionable because incumbent leaders who comprise the organ and who are mandated to impose sanctions may also be the perpetrators of UCGs. In addition to having to potentially judge over their own cases, they may be less inclined to impose sanctions on others by fear of being subjected to the same treatment, or simply by loyalty to other African leaders. In any case, this politicization of the PSC greatly compromises the integrity and viability of the UCG framework.

Given the checkered history of the AU norm on UCG, the present study aims:

- To establish trends and patterns regarding the organization's way of dealing with unconstitutional changes of government through sanctions;

- To examine instances of success/failure with respect to AU's UCG sanctions regime 
- To identify strengths and weaknesses in its theoretical and practical framework, with emphasis on its sanction's regime and;

- To suggest measures to minimise the risk of, or at least better cope with, military coups d'état and other forms of UCG on the continent.

This research attempts to fill the theoretical and practical gap regarding conceptions of, and attention to, sanctions as a tool of peace and security enforcement. Preliminary research suggests that too little informed and critical information currently exists about international organizations of the developing world, that fewer works discuss African institutional attempts to address Africa's problems, with close to none dedicated to the most significant, continental-wide institutions. In light of the on-going unrest and exacerbating conditions within the African region, this research offers significant insight and understanding of conflict in the region through the examination of one of the AU's main, yet often overlooked, coercive tools for regional peace and security. This research contributes to a limited body of literature in international affairs that analyzes the implications of the imposition of sanctions within the African Union and in terms of UCG. It is unique in that it does not seek to assess effectiveness, but rather to establish why in the past sanctions have resulted in the restoration of democratic and institutional order, as well as where the said regime currently stands, in both theory and practice.

Additionally, "as sanctions have become a defining feature of the Western response to several geopolitical challenges" (Masters, 2015), this study seeks to provide an Afrocentric account of their use in peace and security matters. It also fosters reflection on the moral responsibility of African countries, on the hierarchy of regional organizations and on the place of the African Union in international affairs. 
The idea of "African solutions to African problems" has become a "compelling maxim" (Nathan, 2013, p. 48) of the African Union. It "evokes a sense of self-reliance, responsibility, pride, ownership and indigeneity [...] and a neat amalgam of politics, agency and geography" (p. 49). The dictum alludes to the capability and determination of the African continent to solve its own problems without external interference, and may apply to a wide range of issues, including development, health and education. However, it is with regards to peace and security that it is most often used. Acknowledging the requirement for effective crisis management on the continent, the precept is at the heart of the African Union and is embodied in its African Peace and Security Architecture (APSA) and the organs it encompasses. The structure is a clear departure from the operational limitations encountered by the Organization of African Unity, which privileged sovereignty and non-interference in state affairs. The concept of "African solutions" also calls for unity and solidarity among all people of African descent in achieving social, economic and political progress on the continent. These values are at the core of Pan-Africanism (Lobakeng, 2017, p. 1).

Drawing from the maxim and in the context of UCG, this research thus attempts to offer a more realistic picture about the pertinence of the AU's sanctions regime relative to overgeneralized claims regarding the organization's inadequacy to fulfill its mandate.

\subsection{Research questions}

The present research examines the evolution of the AU's sanctions regime regarding UCG, thus answering the following question: what are the implications of AU's current sanctions regime regarding UCG? While the current thesis does not intent 
to provide a thorough analysis of the regime's effectiveness, it does assess the impact of sanctions imposition in response to UCGs by looking at its outcome. Specifically, this study looks at instances where these sanctions have resulted or not in restoration of democratic and constitutional order, with particular the first (military coup d'état against a democratically elected government) and fifth (any amendment or revision of the constitution or legal instruments, which is an infringement on the principles of democratic change of government) instances of UCG, according to related policy and legal instruments.

Moreover, contradictions within the AU's sanctions regime raise several important questions: how are sanctions perceived by the AU? In what instances has the imposition of the latter resulted in the restoration of democratic and constitutional order? What could be improved in the AU's sanctions implementation? This research will endeavor to answer these questions.

\subsection{Methodology}

The two research methods which dominate the study of political studies and social science are quantitative and qualitative in nature. Marvasti (2003) explains that a quantitative research method "involves the use of methodological techniques that represent empirical evidence in numerical categories such as statistics, surveys and experiments" (p. 8). The qualitative research method differs from the quantitative research method in that it falls on the methods of observation, interviewing and analysis of documents gathered from primary and secondary sources such as books, journals, newspaper articles and internet sources (Mouton \& Babbie, 2001, p. 49). 
This dissertation is rooted in qualitative research methods in that it uses the "studied use and collection of a variety of empirical materials, case studies, interviews, artefacts, historical and cultural texts" (Denzin, 2005) to analyze the practice relating to the imposition of targeted sanctions by the AU in response to UCG. In particular, it uses a comparative case study approach with special focus on three countries with a history of UCG: Togo (2005), Mauritania (2008) and Mali (2012). In each case, the facts that triggered the ordering of sanctions are given, the response recorded, and the outcome revealed. The study also presents similarities and differences to compare the handling of the different cases. All three case studies span almost a decade and, following the establishment of the PSC in 2004, have resulted in the restoration of democratic and constitutional order, and are situated in the West African sub-region. West Africa is of particular interest to this research because it has a long history of coups d'état, in spite of having had its colonization era end relatively early and smoothly compared to other parts of the continent. ${ }^{2}$

The material reviewed in this study comprises mainly of the AU's related legal instruments, such as the Constitutive Act of the African Union, the African Charter on Democracy, Elections and Governance, and the Protocol Relating to the Establishment of the Peace and Security Council of the African Union. Regulations, decisions and protocols adopted by the Assembly or the Peace and Security Council are also important sources. The African Union website contains most of these important documents.

\footnotetext{
2 Patrick McGowan has dubbed West Africa the most "coup prone region in the world" (2006:238). His conclusion is supported by the data shown in Table 1, available in appendix A.
} 
All parts of this research are supported by secondary sources from journal articles, newspapers, books, reports and other relevant scholarly publications. The research is also based on secondary literature from academic, civil society and African Union sources as well as doctrine. The findings speak to the AU's sanctions regime more broadly to identify trends, patterns, strengths and weaknesses. Qualitative methods are used to answer the research questions.

\subsection{Scope and limitations}

Through the dissertation, four situations are studied in an attempt to illustrate the probable role that the organization can play when addressing UCGs through sanctions. The current thesis does not offer a comprehensive exposition of sanctions - despite it seeking to present general trends and patterns in the AU's regime. However, it takes as its starting point the African Union's framework of rules regarding sanctions. The legal basis for the AU to impose sanctions, the different types of sanctions the AU can use and the rules providing legal powers to the $\mathrm{AU}$ organs to take the necessary decisions are key themes that will be examined. While providing political context regarding each case study, the dissertation does not look more broadly into reasons for why unconstitutional change of government happen.

Another limitation of the study is the period and region under investigation. Some of the rules now in force as a part of the African Unions sanctions regime were established under the OAU. However, the OAU is not the focus of this study and will therefore not be studied in depth or compared with the current Union's regime. 
Moreover, this essay attempts to stray away from the mostly normative debate (e.g., the effectiveness of sanctions implemented) which currently dominates literature on the subject. An assessment is made, to some extent, when examining the outcome of $\mathrm{AU}$ actions against UCGs; yet, conclusions made in light of said examination are intended to be more descriptive than evaluative. The effectiveness of sanctions depends on a variety of factors, part of a very complex field of study on which the current investigation does not center. This study primarily seeks to draw from past cases of sanctions application by the AU in order to outline the characteristics of its current sanctions regime and offer future solutions for improvement.

Finally, while it is not possible to consider West African states as a whole, since they experience different dilemmas caused by internal and external complexities, they still present common threads which can be helpful in understanding the AU's response mechanisms (here, sanctions) to political movements and shifting power dynamics in the region, as well as how such responses can be improved. Moreover, this dissertation offers general conclusions regarding the AU's response to UCGs on the continent, however, additional research should be conducted beyond the West African region. The availability of information is also a factor when considering the choices of case studies and the overall topic. 


\subsection{Structure}

The dissertation is divided into seven chapters.

Chapter one introduces the research topic: the background and purpose of the study, the research questions, the methodology employed in collecting data, as well as the limitations and scope of the research are presented.

Chapter two defines the concept of sanctions, both in the policy/legal and academic literature. The evolution of the concept and the different types of sanctions employed are investigated, focusing on the post-Cold War era.

Chapter three presents an overview of the evolution, development and structure of the African Union, with a brief outline of its predecessor, the Organization of African Unity. Notably, the organs and their purposes are outlined.

Chapter four discusses UCGs, specifically within the African context, and the AU's response to it through sanctions, demonstrating the ways in which the AU sanction policy managed to restore its policy objectives. Attention is given to the AU's legal instruments, including the 2000 Lomé Declaration.

Chapter five examines the three case studies, presenting similarities and differences in the handling of the different cases.

Chapter six provides an analysis of the AU's sanctions regime by identifying strengths, weaknesses and patterns, as well as by exploring potential solutions to address its shortcomings. Drawing from the findings, the study then tackles the idea of "good coups" - where "coup leaders are seen to be genuinely acting in the public interest" (Ikome, 2007, p. 19) - within the African context, as well as the role of the AU in that regard. It does so by looking at the case of Zimbabwe. 
Chapter seven, as the concluding chapter, gives an overview of the key findings made by the study and offers recommendations to improve the 2009 Ezulwini Framework for the Enhancement of the Implementation of Measures of the African Union in situations of Unconstitutional Changes of Government. 


\section{Chapter 2: Sanctions}

Clarification with regards to the concept of sanctions needs to be provided in order to adequately study the African Union's sanctions regime. The conceptualization is important to understand why sanctions are used, as well as which types are favored today, and why. In the African context, the clarification will further help in better understanding the manner in which the AU perceives and responds to peace and security challenges, including UCG.

This chapter thus serves as a conceptual framework for this dissertation. The first section provides a definition and brief overview of the concept of sanctions, while the second section looks at the different types of sanctions, providing an outline of their evolution, as well as their respective purpose and limitations. The third section offers a review of the concept within the literature, focusing on the notion of effectiveness and outlining the gaps in its academic assessment.

When looking at sanctions as a response to UCG, most of the discussion in both the popular press and the scholarly literature focuses on the purpose of sanctions in terms of their ability to change the behavior of the target(s). This research follows the same rationale, keeping in mind that sanctions tend to be imposed for a variety of different purposes.

\subsection{Defining sanctions}

According to Daoudi and Dajani (1983), sanctions are a "collective action against a state considered to be violating international law" designed "to compel that state to conform [to the law]" (p. 5-8). Often perceived as an intermediate measure between 
diplomacy and military force, their traditional purpose is to support peaceful transitions, deter non-constitutional changes, constrain terrorism, protect human rights and promote non-proliferation (McMahon, 2006). While the objectives sought often vary, most sanctions today are targeted in order to maximize the impact on the responsible individual(s).

Sanctions are frequently applied by the United Nations Security Council (UNSC), and regional organizations such as the AU, the Economic Community of West African States (ECOWAS) and the European Union (EU), with Africa being the most targeted region. In past decades, regional cooperation has been increasingly concerned with core political issues such as peace and security, democratic and constitutional order, and good governance, partly in response to the United Nations' shortcomings when dealing with international crises (Fawcett, 2004, p. 432).

There are two principal types of sanctions: targeted and comprehensive. While references made to sanctions date back to ancient Greece, where they manifested in the form of trade embargos, it is not until the mid-1990s that they moved from comprehensive measures to targeted sanctions aimed at individuals and small groups or entities. This shift, initiated by the United Nations (UN), was done in part to reduce collateral damage to the local population (Collins, 2009, p.4).

\subsection{Typology of sanctions}

Sanctions are usually grouped into three categories: economic sanctions, political sanctions and targeted (or smart) sanctions. The first two are generally considered 
comprehensive because they involve the entire population, while the latter target the political leaders or individuals at fault. Each category is discussed in depth below.

\subsubsection{Economic Sanctions}

Economic sanctions are one of three main strategies of international economic pressure, along with trade wars and economic warfare. ${ }^{3}$ They are defined as "the withdrawal of customary trade and financial relations for foreign and security purposes" (Masters, 2015). In practice, governments and multinational bodies use economic sanctions to reduce the ability of a target state to carry out policies which are contrary to international norms and practices (Farrall, 2007, p. 107). In addition to refusing to sell or purchase goods from the targeted state, they may also suspend financial transactions and freeze national assets held abroad (Farrall, 2007, p. 107).

Defined as prohibiting the sale of weapons to a targeted state, arms embargoes are the most frequently used form of economic sanction and among the most common types of targeted sanctions (Hufbauer, Schott, Elliott \& Oegg, 2007, p. 139). The UN identifies two types of arms embargoes: voluntary and mandatory. While the former relies on member states' goodwill, the latter requests member states to stop supplying weapons to rogue states (Strandow \& Wallensteen, 2007, p. 1).

Mineral sanctions refer to sanctions that forbid the targeted state from exporting the minerals that it produces, as well as to export services or equipment associated with

\footnotetext{
${ }^{3}$ According to RA Pape, "trade war is when a state threatens to inflict economic harm or actually inflicts it in order to convince the target state to agree to terms of trade more favourable to the coercing state. [...] Alternatively, economic warfare seeks to weaken an adversary's aggregate economic potential in order to weaken its military capabilities, either in a peacetime arms race or in an ongoing war." (1997:94)
} 
mineral extraction. Mineral sanctions include diamond sanctions which are applied against a diamond producing state; the 2003 UN Security Council Resolution 1521 against Charles Taylor's regime in Liberia, who was accused at the time of using conflict diamonds to sponsor the rebel movement against the Sierra Leone government, is a noted example (Renner, 2002, p. 22).

Critics of economic sanctions point out that they may be more harmful to the local populations which they are intended to help rather than to the governments they are meant to influence. They can also harm the country imposing the sanctions, in addition to prompting the targeted country to impose retaliatory sanctions. Moreover, skeptics argue that economic effects of economic sanctions, including arms embargos and mineral sanctions, rarely cause a political reconsideration, and can even result in the sanctioned state becoming more independent economically (Trachsler, 2010, p. 2).

\subsubsection{Political Sanctions}

Farrall (2007) defines political sanctions as "actions that seek to interrupt the target's relations with the "external world in areas apart from basic trade" (p. 123). Political sanctions may involve the suspension of all diplomatic contacts with the targeted state or simply a reduction in diplomatic presence (also known as diplomatic sanctions).

Other examples include limiting or cancelling high-government visits of the targeted state and expelling its diplomatic missions. Some sanctions can also result in the suspension of the rogue regime from international and regional organizations (Farrall, 2007, p. 123).

Aviation sanctions are another type of political sanctions prohibiting flights from entering a targeted state in order to reduce international access. Similarly, sporting 
sanctions forbid rogue states from participating in international sporting events, as was the case in 1964, when the International Olympic Committee banned South Africa from taking part in the Olympic Games because of its Apartheid laws.

\subsubsection{Targeted sanctions}

As mentioned earlier, "comprehensive sanctions employ full trade embargos against the target of sanctions and involve wide-sweeping bans on trade, diplomatic relations, and or other relationships between target and sender." In contrast, targeted sanctions impose embargos on determined items or restriction on individuals or on groups of specific individuals (McLafferty, 2011).

Three major factors prompted the shift towards targeted sanctions as an established practice in international relations. First, comprehensive sanctions gained a negative reputation, following the cases of Iraq, Rwanda and Yugoslavia in the 1990s; not only did sanctions prove often ineffective in changing regimes, but they even entrenched in power the groups they were intended to undermine (Giumelli, 2015, p. 1352-1353). This was notably the case for Saddam Hussein whose position was made more secured following the implementation of comprehensive economic sanctions against Iraq, as well as in Haiti, where the sanctions imposed against the military junta sparked negotiations but did not succeed alone in containing armed violence or changing policies (Cortright, Lopez \& Gerber, 2002). Lastly, sanctions were more detrimental to civilians than to the elites whose behavior the measures sought to alter. These doubts were further justified by various reports from newspapers, governments and international 
organizations, decrying the deaths of 500,000 Iraqi children as a result of UN comprehensive sanctions. Targeted sanctions were also facilitated by the emerging principle of individual international responsibility, solidified by the creation of the Special UN Change Criminal Tribunal in the 1990s and the International Criminal Court in 2002 Cortright, Lopez \& Gerber, 2002).

Seeking to address these concerns, targeted sanctions focus on punitive measures (such as asset freezes, travel bans, and embargoes within a specific trade sector) and apply to targeted individuals and entities to minimize unintended social and economic consequences for the vulnerable population.

Yet, targeted sanctions have drawn criticism regarding their compatibility with other principles of international law, namely the principle of non-intervention and state sovereignty, in addition to raising concerns about human rights violations. Questions have also been raised with regards to their implementation, both in terms of evenness and uniformity, as well as effectiveness, particularly in comparison with comprehensive sanctions.

\subsection{Literature review}

One of the most definitive studies on sanctions' effectiveness, which covered the period 1915 to 2006, has shown that comprehensive sanctions are effective in changing the behavior of national leaders at best $34 \%$ of the time, and that the more comprehensive the level of sanctions, the lower the degree of success (Wagner, 2015). The African Affairs political science literature generally agrees that a main reason for the failure of comprehensive sanctions is that they are often regarded as a sign of foreign hostility by 
the target's population. Even in countries with repressive regimes, "[comprehensive] sanctions tend to boost internal cohesion, creating a "rally-round the-flag" effect" (Tostensen \& Bull, 2002, p. 397). Another problem is the collateral damage to the civilian population in the target country, as well as to third countries generally, which often weakens support for sanctions. Moreover, elites in target countries generally consider targeted sanctions as less tolerable than comprehensive ones. Data has shown that the longer sanctions are in place, the less likely they are to be effective, as the targeted state tends to adapt to its new economic circumstances instead of changing its behavior (Hovi, Huseby \& Sprinz, 2005). In addition, sanctions are rarely watertight and there are often strong commercial incentives to evade them.

According to the literature, a constant concern surrounding sanctions is the adverse effects that they can have. As cautioned by former secretary-general Boutros Boutros-Ghali, "they raise the ethical question of whether suffering inflicted on vulnerable groups in the target country is a legitimate means of exerting pressure on political leaders whose behavior is unlikely to be affected by the plight of their subjects" (1995). This sentiment is fueled in part by the UN's checkered history with sanctions, which includes "the organization's worst scandal—linked to the Iraq oil-for-food program ${ }^{4},-$ as well as numerous poorly enforced measures aimed at blocking the flow of weapons to Africa's civil war combatants during the 1990s" (McMahon,

${ }^{4}$ Established in 1995, the UN oil-for-food program allowed then-President Saddam Hussein to trade controlled amounts of oil to buy food and other essential supplies. This was instituted in order to relieve the extended suffering of the civilian population as a result of the U.S.-led economic sanctions imposed after Saddam Hussein's 1990 invasion of Kuwait. However, throughout its existence, the oil-for-food program was alleged to have been corruptly administered by the former Iraqi leader and the UN, with profits being unlawfully diverted to the government and to UN officials. The program was terminated in 2003, following the lifting of the UN sanctions. 
2006). UN sanctions, mainly in the form of arms embargoes, have had a poor track record for many African States, like Somalia and Rwanda in the early 1990s, or during initial efforts to halt the flow of arms into devastating civil wars in Angola and Sierra Leone.

The literature suggests that governments in many parts of the world view sanctions with skepticism, mainly due to its asymmetry and its unintended negative impact on population rather than culpable elites. The UN Security Council voted for economic sanctions twelve times in the 1990s, nearly as many times as during the first 90 days of the $20^{\text {th }}$ century. UN Secretary-Generals Boutros Boutros-Ghali and Kofi Annan both labeled sanctions a 'blunt instrument' and asked whether the suffering inflicted on vulnerable groups was a legitimate means of exerting pressure on political leaders (Hawkins \& Lloyd, 2003, p. 444). The failure of sanctions to yield immediate results in Iraq also caused the scholarly work into economic sanctions to shift in new directions. By this juncture, the bulk of sanctions scholarship had not been seen as terribly useful to policymakers. The most high-profile debate centered on the question of whether sanctions "worked" as a policy tool. Hufbauer, Scott and Elliott (1990) developed the first large-N data set (HSE) and concluded that sanctions succeeded $34 \%$ of the time. Research emanating from disparate theoretical and methodological perspectives sympathizers (Kaempfer \& Lowenberg, 1998; Lowenberg \& Mertens, 2004; Kirschner, 1997; Buck, Gallant \& Nossal, 1998) came to similar conclusions, stating that comprehensive sanctions disproportionately hurt politically weak groups and benefit the target regime. Additionally, a number of sanctions scholars argue that economic sanctions have minimal effect on authoritarian targets (Brooks, 2002; Allen, 2005, 2008; 
Lektzian \& Souva, 2007); smart sanctions that hurt key elites, on the other hand, would have a better chance of success without hurting the target country's general public.

Smart (or targeted) sanctions increasingly became the policy tool of choice to minimize the unintended negative effects of embargo and sanction regimes on civilian populations, while still applying international pressure to individuals, governments and firms that violate international law.

Targeted sanctions are designed to focus on punitive measures (such as asset freezes, travel bans, and embargoes within a specified trade sector, e.g., arms) among government officials and associated elites while attempting to protect innocent groups for the larger effects of these measures. Recent research on the impact of economic coercion in the target country would appear to support the humanitarian arguments in favor of smart sanctions. Peksen and Drury (2009) find that the implementation of economic sanctions triggers drops in democracy and human rights scores in target governments. Peksen (2009) also shows that sanctions lead to a decline in the physical integrity rights of individuals in target countries. Furthermore, the decline in those rights is greater if comprehensive sanctions are imposed rather than targeted sanctions. Yet, a number of studies are less positive with regards to the effectiveness of targeted sanctions. For one, most, if not all, of the econometric literature of the 2000s (Bolks and Al-Sowayel, 2000; Brooks, 2002; Allen 2005, 2008b; Lektzian \& Souva, 2007) agrees that if the target state is democratic, comprehensive sanctions are most likely to trigger quick concessions "since they face more constraints in developing effective counter-sanctions measures" (Jeong, 2018). Furthermore, Tostensen and Bull (2002) find that the optimism regarding the effectiveness of smart sanctions appears to be largely unjustified. In his literature 
review of smart sanctions, Drezner (2011) asserts that they are less promising than comprehensive sanctions in coercing the target government into making a concession. Similar conclusions are reached by Lopez and Cortright (2002b) after reviewing the record of United Nations sanctions implemented in the 1990s.

Globalization has significantly altered the international sanctions regime, in some instances, complementing old players, i.e., the UN, with new actors. Increasingly, regional organizations such as the $\mathrm{AU}$ and the European Union (EU) began imposing sanctions against regimes that violated international norms and practices. The post-Cold War sanctions regime has also seen the rise of global NGOs who lobby the international community to sanction states that disregard international norms and practices.

Finally, organizations such as the Washington-based International Institute of Economics (IIE) and the International Peace Academy have been conducting their own independent research on the achievements of both multilateral and unilateral sanctions. Their findings insist that only a small portion (around 5\%) of the international sanctions imposed on targeted states have been successful. According to the IEE report, sanctions fail because "it is difficult to secure universal participation in embargoes". Furthermore, it is also difficult to monitor the compliance of states that have agreed to participate (Cortright \& Lopez, 2002, p, 16).

While the key role of regional organizations in applying sanctions has been acknowledged in the literature, studies remain centered on their role under the umbrella of the UN, often overlooking the growing centrality of regional arrangements such as the AU in regional security governance, and peace and security enforcement. Despite these 
gaps, a limited body of literature looking at the AU sanctions' regime on the continent is slowly emerging.

\subsection{Conclusion}

This chapter served as a conceptual framework for this dissertation by defining the idea of sanctions. It was established that sanctions can either be comprehensive and targeted, serve various goals and take various forms. It was also found that sanctions are mostly used by the UN, along with regional organizations, to restore and maintain international peace and security, and to alter the behavior of a regime in violation of international norms and human rights. Today, targeted sanctions are the most commonly used category of sanctions, due to their reduced adverse effects. However, targeted sanctions have also drawn criticism regarding their implementation and compatibility with international principles. Lastly, a literature review of the concept was provided, through which a lack of work regarding the independent role of regional organizations, namely the AU, when applying sanctions was noted. 


\section{Chapter 3: The African Union}

This chapter offers a contextual analysis of the African Union by looking at its structure and function, specifically regarding peace and security maintenance in Africa. First, the establishment and mandate of the organization is laid out, with reference made to its predecessor, the Organization for African Unity (OAU). A synopsis of the AU's organs and their respective role is then examined, together with the regional economic communities active on the continent. For the purpose of this dissertation, emphasis is made on the Economic Community of West African States (ECOWAS).

\subsection{Establishment of the African Unity: the Organization of African Unity}

The Organization of African Unity was founded in 1963 amidst the decolonization process and anti-apartheid struggle started on the continent. At that time, the then newly independent African states agreed upon creating an Assembly of Heads of State and Government (AHSG), the paramount organ of the OAU, with the Council of Ministers and Secretariat below. Other organs included the Commission on Mediation, Conciliation and Arbitration, as well as a number of specialized commissions on education, defense, science and economic affairs (OAU Charter, art. 8). The OAU's main objective was to bring about change and freedom for African states by eliminating the last remnants of colonialism. The organization sought to promote the principles of selfdetermination, sovereignty, integrity and dignity, free from all forms of interference. It also sought to foster African unity and solidarity, as well as international cooperation (OAU Charter, art. 2). 
Among the reasons cited for the OAU's challenges in fulfilling its mandate were: its strict defense of members' sovereignty and the principle of non-interference in internal affairs; its inability to resolve civil wars and other violent conflicts; its deliberate decision to constrain the power of the Secretary-General; and the ideological and political divides between member states (Kufuor, 2005, p. 133).

As a result of these setbacks, the AHSG produced the Sirte Declaration in September 1999, which established a new pan-African body, the African Union (Engel \& Porto, 2009, p. 83), "to forge unity, solidarity and cohesion, as well as cooperation, between African people and among African States” (Sirte Declaration, clause 3).

\subsubsection{African Union: birth and mandate}

The African Union was established on May 26, 2001 in Addis Ababa and launched on July 9, 2002 in Durban, South Africa. Its Constitutive Act was adopted in July 2000 in Tomé and ratified by all Member states by March of the following year. The Constitutive Act of the African Union replaced the OAU Charter as the fundamental act of the union, and contains articles on its main organs, responsibilities and purposes.

Modeled after the European Union (EU), the AU is intended to provide a legal and institutional framework to address the challenges of the post-Cold War era (Magliveras \& Naldi, 2002, p. 415) and to promote an integrate prosperous and peaceful Africa. Articles 3 and 4 of the Act define respectively the objectives and principles of the Union, reaffirming core principles such as regional integration; peace and security; protection of human rights; non-intervention; legitimate intervention; and respect for democracy and the rule of law (Constitutive Act of the AU, art. 4). 


\subsection{Structure}

The organs and institutions of the African Union are defined and described in Articles 5 through 22 of the Constitutional Act. They are identified as followed: (1) the Assembly of the Union; (2) the Executive Council; (3) the Pan-African Parliament; (4) the Court of Justice; (5) the Commission; (6) the Permanent Representative Committee; (7) the Specialized Technical Committees; (8) the Economic, Social and Cultural Council; and (9) the Financial Institutions. Additionally, the Peace and Security Council, the standing organ of the AU for the prevention, management and resolution of conflicts, was later established through article 20 of the Constitutive Act, together with Article 2 of the 2002 Protocol Relating to the Establishment of the Peace and Security Council (PSC) of the African Union.

The following section examines in more depth the institutions of the AU. Emphasis is made on the Assembly and the PSC, due to their central role in implementing sanctions. Moreover, for the purpose of this dissertation, the Permanent Representative Committee, the Specialized Technical Committees and ECOSOC are only presented summarily.

\subsubsection{Assembly of the Union}

The Assembly is the supreme decision-making organ of the African Union. Based in Addis Ababa, it is composed of all Heads of its member states or their accredited representatives. The Assembly meets once a year in ordinary session but can meet in extraordinary session at the request of member states by two-thirds majority approval. All 
decisions of the Assembly are made either by consensus or by a two-thirds majority (Constitutive Act of the AU, art. 6).

The Assembly is led by a Chairperson elected among the heads of states for a period of one year. The Chairperson is responsible, inter alia, to convene the sessions of the Assembly, guide the proceedings of the Assembly, rule on point of order and in consultation with the Chairperson of the Commission represents the Union in between sessions. The Chairperson is supported by the Bureau, composed of 14 ViceChairpersons elected based on geographical distribution (Constitutive Act of the AU, art. $6)$.

The functions of the Assembly are to determine the common policies of the Union; to establish its priorities and to give directives to the Executive Council and the Peace and Security Council on matters related to conflict prevention and management, and other urgent situations. The Assembly further monitors the implementation and decisions of the other organs and decides upon any and all interventions in a Member State. Other roles are to establish the budget of the Union; consider requests for membership; establish new organs within the $\mathrm{AU}$; and appoint or terminate the appointment of the Judges of the Court of Justice (Constitutive Act of the AU, art. 9).

The Assembly is involved in the decision to apply sanctions against UCGs, as prescribed by Rule 36(1) of the Rules of Procedure of the Assembly of the Union. It imposes sanctions upon recommendation by the Executive Council. 


\subsubsection{Executive Council}

The Executive Council works in support of the Assembly and answers to it. It is composed of the Ministers of Foreign Affairs, or such other Ministerial or authorities, as designated by the governments of member states. According to Article 13 of the Act, the main functions of the Executive Council involve coordinating and deciding on policies in areas of common interest to member states; and considering issues referred to it and monitoring the implementation of policies formulated by the Assembly. Notably, the Executive Council recommends the Assembly to impose sanctions and applies them, per Rule 36(1) of the Rules of Procedures of the Assembly.

The Executive Council has the power to make its own binding decisions in policy areas of common interests such as health, environment, transport and communication, humanitarian response and foreign trade. The Executive Council is assisted by the Permanent Representative Committee and the Specialized Technical Committees of the AU.

\subsubsection{Pan-African Parliament}

Founded on the basis of the 1961 Treaty Establishing the African Economic Community that came into force in 1964, the Pan-African Parliament (PAP) was established in 2004 in Addis Ababa. The Constitutive Act of the African Union provides a separate protocol for the establishment of the PAP regarding its composition, functions and jurisdiction (Constitutive Act of the AU, art. 17). 
The PAP is mandate to ensure the full participation of African peoples in governance, development and economic integration of the continent; and to promote democracy, prosperity and peace on the continent (Constitutive Act of the AU, art. 17).

The Pan-African Parliament is composed of five elected Parliamentarians from the Parliament or equivalent legislative organs of each member state, who serve concurrently with their tenure at their national parliament. The President is elected every five years.

Furthermore, article 18 of the PAP Protocol stipulates that the PAP "shall work in close collaboration with the Parliaments of the Regional Economic Communities and the National Parliaments or other deliberative organs of Member States" (Constitutive Act of the $\mathrm{AU}$, art. 17).

The Constitutive Act of the African Union states that "the composition, powers, functions and organization of the PAP should be defined in a specific protocol" (Constitutive Act of the AU, art. 17). Said protocol was approved in March 2001 and entered in force in November 2003. While the protocol extends the PAP's mandate to also include political matters and envisioned that the organ would evolve into an institution with full legislative powers, its current mandate is to exercise advisory and consultative powers within the AU. As a result, it bears minimum influence over the application of sanctions in cases of UCG (Förander, 2010, p. 17-18).

\subsubsection{The Courts of the Union}

The establishment of the Court of Justice under Article 18 of the Act represents a significant departure from the OAU Charter which never envisioned a judicial organ. 
While provisions are made regarding the Court for the adjudication of interAfrican disputes, the Constitutional Act does not provide any details on the AU Court's composition and functions, leaving them to be determined by a future protocol. The Protocol of the Court of Justice of the African Union was eventually adopted on July 11, 2003 (Magliveras \& Naldi, 2002, p. 421).

Among other things, the Protocol identifies the eligible parties to submit cases, the jurisdiction of the Court and the different sources of law. According to the Protocol, the Court is given competence over interpretation and application of the Constitutive Act, as well as all treaties and legal instruments within the AU and between its member states. The Assembly may also confer a special jurisdiction over the Court. Decisions made by the Court are binding upon its member states. The parties eligible to submit cases to the Court are all AU member states which have signed and ratified the Protocol Establishing the Court; the Assembly; the Pan-African Parliament; the Commission; and other organs authorized by the Assembly. Third parties may also submit cases under specific circumstances (Protocol Establishing the Court of Justice, art. XVIII).

Another important Court within the AU framework is the African Court of Human Rights and Peoples' Rights. Based in Arusha, Tanzania, it was established in 2006 to deal with human rights cases between states and citizens, as part of the African Human Rights System (Magliveras \& Naldi, 2006, p. 190).

In July 2004, the Assembly decided to merge the African Court of Justice and the African Court of Human Rights and Peoples' Rights into the African Court of Justice and 
Human rights, which would be the main judicial organ of the African Union. Its founding document, the Protocol on the Statute of the African Court of Justice and Human Rights was adopted in 2008 , with provision to enter into force thirty days after the deposit of instruments of 15 member states. However, at the time of this writing, the Protocol does not have legal force and effect as only six countries have ratified the Protocol (Botswana, Burkina Faso, Congo, Libya, Liberia and Mali). As a result, the African Court on Human and Peoples' Rights remains operational pending its future merger with the Court of Justice. $^{5}$

\subsubsection{Commission}

The Commission is an administrative wing accountable to the Assembly and the Executive Council. It is the Secretariat of the AU entrusted with executive functions and day to day management of the organization. Among its main tasks are monitoring the implementation of the decisions of the policy organs of the AU and preparing strategic plans to be considered by the Executive Council, in sync with current programs and policies of the Union and the Regional Economic Communities (Statute of the Commission of the AU, art. 3). The Commission is also tasked with supporting the Peace and Security Council by monitoring and reporting developments in member states where UCGs have taken place, in accordance with article 10 of the Protocol relating to the Establishment of the Peace and Security Council.

\footnotetext{
${ }^{5}$ See African Union (Assembly of Heads of State and Government) 'Decision on the Seats of the African Union' (Addis Ababa 2004) AU/Dec.45 (III) art 4; African Union (Assembly of Heads of State and Government) 'Decision on the Merger of the African Court on Human and Peoples' Rights and the Court of Justice of the African Union’ (Sirte 2005) Assembly/AU.Dec.83 (V).
} 
The Commission is composed of the Chairperson, the deputy Chairperson and eight Commissioners, all of whom are appointed by the Assembly based on gender and sub-regional representation (Statute of the Commission of the AU, art. 2(1)). The Commission is located at the AU headquarters in Addis Ababa, Ethiopia.

In 2009, the Assembly set a process in motion to transform the Commission into the AU Authority with more extensive powers. Notably, the new Authority is expected to coordinate defense, foreign relations and trade policies, among other things. As of 2018, the process is still underway (Viljoen, 2012).

\subsubsection{Peace and Security Council}

Unlike the other AU institutions, the Peace and Security Council (PSC) was not established by the AU Constitutive Act, but rather by its own protocol. Adopted by the Assembly in 2002, the Protocol relating to the establishment of the Peace and Security Council (PSC Protocol) entered into force on December 26, 2003, replacing the OAU's Central Organ of the Mechanism for Conflict Prevention, Management and Resolution. ${ }^{6}$

The PSC is a "permanent decision-making organ of the AU for prevention, management and resolution of conflicts in Africa. It is located at the headquarters of the African Union" (Aneme, 2010) in Addis Ababa, Ethiopia.

The PSC is comprised of fifteen member states (ten for a two-year period and five for three years), elected by the Executive Council and endorsed by the Assembly based on

\footnotetext{
${ }^{6}$ See African Union (Assembly of Heads of State and Government) 'Decision on the establishment of the Peace and Security Council of the African Union' (Durban 2002) Ass/AU/Dec.3(I); Protocol relating to the establishment of the Peace and Security Council of the African Union (adopted 09 July 2002, entered into force 26 December 2003).
} 
equitable regional representation and national rotation. While there is no provision regarding permanent and non-permanent members, member states of PSC are expected to meet certain criteria to apply, including respect for the rule of law and constitutional governance; protection of human rights and commitment to honor financial obligations to the AU (Protocol Relating to the Establishment of the Peace and Security Council of the AU, art. 5 (2)). Article 3 of the Constitutive Act outlines amongst the PSC's objectives the promotion of peace, security and stability by anticipation and the prevention of conflicts.

While the Council is instructed to use mediation, consultation and dialogue in case of conflict, it also has extensive powers to mount and deploy peace support missions, as well as to recommend an intervention in a member state to the Assembly, pursuant to the rules on crimes against humanity, genocide and war crimes. Decisions made by the Peace and Security Council are binding to all AU members. Most important to this dissertation is the PSC's authority to impose sanctions against an unconstitutional change of government, as prescribed by Article 7(1) of the Act. In that sense, it is the most important organ of the AU for matters pertaining to UCGs. In March 2009, the Peace and Security Council established a Committee on Sanctions, in accordance with Article $8(5)$ of the PSC Protocol, whose functions would be to administer, monitor and implement sanctions. The Committee has yet to be operationalized at the time of this writing (Norwegian Embassy to Ethiopia, 2009).

In addition to working with the various AU organs such as the Assembly, the PanAfrican Parliament and the African Commission on Human and Peoples' Rights, the PSC 
is a central piece of the African Peace and Security Architecture (APSA), a series of norms and mechanisms to advance peace and security on the continent. Other organs also included in the APSA are the AU Commission, the Peace Fund, the Continental Early Warning System, the Panel of the Wise, the African Standby Force and the Military Staff Committee (Protocol Relating to the Establishment of the Peace and Security Council of the AU, art. 5(4)). The African Peace and Security Architecture is further discussed in chapter four.

\subsubsection{Other Organs: Permanent Representative Committee, Specialized Technical}

\section{Committees, ECOSOCC}

The Permanent Representative Committee serves as an advisor body to the Executive Council and carries most of its practical activities involving sessions preparation, proposals drafting, communication liaison and budget implementation.

The several Specialized Technical Committees are responsible for the preparation and coordination of the projects and programs of the Union, and the supervision and follow-up of its policies (Constitutive Act of the AU, artc. 13(3).

The AU Economic, Social and Cultural Council (ECOSOCC) is an advisory body of civil society representatives, professional and cultural groups both in Africa and in the Diaspora. The institution is mainly tasked with the promulgation and implementation of 
AU norms and policies. It also acts as a liaison among Africa's population on common issues of the continent. ${ }^{7}$

Neither of these organs are involved in the handling of UCGs and the imposition of sanctions.

\subsubsection{Finances}

Article 19 of the Constitutive Act of the AU envisioned the establishment of the African Central Bank (ACB), the African Monetary Fund (AMF) and the African Investment Bank (AIB) as the three new financial institutions under the Union. The role of these institutions is to facilitate the economic integration called for in the 1991 Treaty Establishing the African Economic Community. So far, the AU Assembly has adopted protocols for the establishment of the AIB and AMF; however, the draft protocol for the establishment of the ACB has not yet been submitted to the Assembly. Proposed structures will be submitted to the Executive Council for approval once the protocols for each institution comes into force. ${ }^{8}$

\footnotetext{
${ }^{7}$ See African Union (Assembly of Heads of State and Government) 'Statutes of the Economic, Social and Cultural Council of the African Union' (Addis Ababa 2004) AU/Dec.48 (III) arts 2 \& art 3(2) which enumerates the members of ECOSOCCC.

${ }^{8}$ See African Union (Assembly of Heads of State and Government) 'Decision on the Location of the Headquarters of $\mathrm{AU}$ institutions in various AU Regions of the Continent' (Abuja 2005) Assembly/AU/Dec.64 (IV) art 3. During that same session, it was noted that the Northern Region had agreed that Libya should host the Investment Bank; see also African Union (Executive Council) 'Decision on the Interim Report on the establishment of Financial Institutions' (Khartoum 2006) EX.CL/Dec.242 (VIII) where the Executive Council requested the two other sub-regions to identify the host state for the sub-regions. The Executive Council also requested the Commission to set up Technical Steering Committees for the establishment of the institutions.
} 
The African Union is mainly financed by member states and partners, however many AU member countries default either partially or completely their annual dues. Traditionally, the five main contributors were Algeria, Egypt, Morocco (previously Libya), Nigeria and South Africa, which accounted for over $65 \%$ of the total AU budget. As a result, many have noted that "the unbalanced financing of the union has led to a marginalization of the smaller countries and an increased role for the main donors" (Förander, 2010, p. 23). More recently, these five countries have continued to face significant internal and external challenges, resulting in an increase of the Union's dependency on partner financing, including the EU, the United States, the World Bank and China. Today, their contributions account for over $70 \%$ of the AU budget (Miyandazi, 2016).

Under existing agreements, the Union budget continues to be underfunded by both Member States and Development partners. Article 23 of the Constitutional Act authorizes the Assembly to impose sanctions on member states that defaults on their annual contribution to the budget. In the past, sanctions have been imposed against Member states in arrears, even though most of their involvement in AU activities had been questionable due to internal strife (Magliveras, 2011). 
Illustration 1 Gap between the planned Commission budget and actual budget that is funded by both member states and Partners: 2011-2015

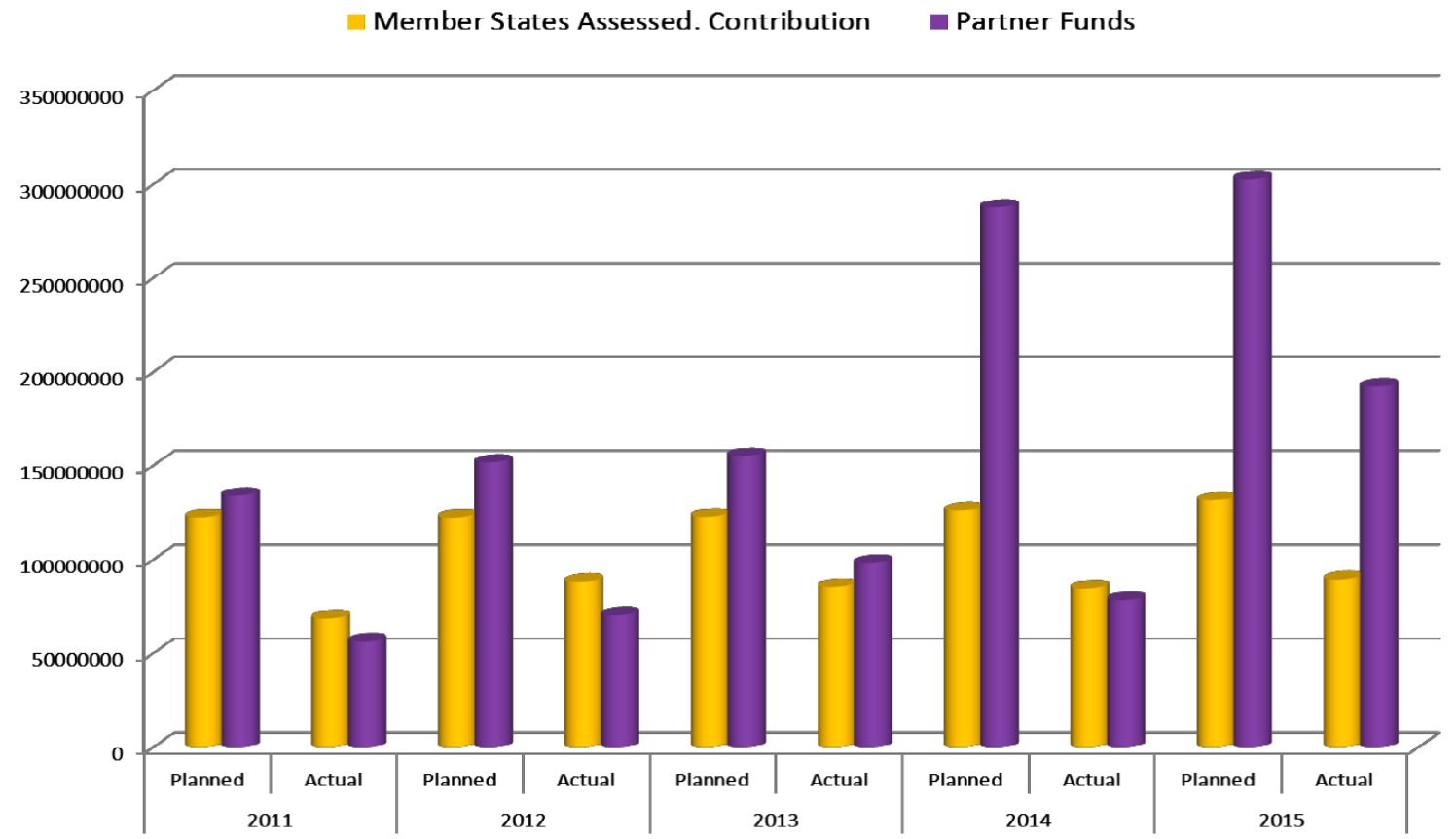

Source: AU (African Union). 2016. "Financing of the Union” [Online]. Available at : https://au.int/en/financingau [Accessed 15 June 2018]

The Peace and Security Council is mainly financed by the voluntary Peace Fund established under the PSC. Member states were initially expected to provide $6 \%$ of total AU contribution to the Fund but that number was increased to $12 \%$ by 2014 at the 2010 AU Summit. So far, the main donor has been the European Union (Engel \& Porto, 2009, p. 91).

The Financing of the Union decision was adopted during the $27^{\text {th }}$ African Union Summit held in Kigali in 2016. The Decision directs all African Union Member States to implement a $0.2 \%$ levy on eligible imports such as agricultural fertilisers and seeds, industrial machinery and medical equipment, from non-Member states to finance the Union. The levy is to be instituted to reduce dependency on partner funding and to finance $100 \%$ Operational Budget, 75\% Program Budget and 25\% Budget of Peace 
Support Operations of the African Union. As of 2018, at least 14 African Union member states have been collecting the levy (Background Paper on Implementing the Kigali Decision on Financing the Union, 2016).

\subsection{Regional economic communities}

While there are currently over ten sub-regional organizations in Africa, the African Union recognizes only eight: the Economic Community of West African States (ECOWAS), Common Market of East and Southern Africa (COMESA), the Economic Community of Central African States (ECCAS), the Southern African Development Community (SADC), the Inter-Governmental Authority for Development (IGAD), the Arab Maghreb Union (AMU), the Economic Community of Sahelo-Saharan States (CEN-SAD) and the East African Community (EAC).

Article 3(1) of the Constitutive Act as well as the Protocol on relations between the African Union and the Regional Economic Communities regulate in detail the cooperation between the $\mathrm{AU}$ and the different regional organizations. The Peace and Security Council Protocol stipulates that sub-regional organizations are part and parcel of the continental security architecture (art. 16(1)), with the African Common Defense and Security Policy outlining the role of sub-regional organizations in implementing AU norms on the prevention, management and resolution of conflict under the umbrella of the PSC (Solemn Declaration on a Common African Defense and Security Policy, art. 26 and 27). The Lomé Declaration on the framework for an OAU response to unconstitutional changes of government further prescribes that the OAU should "enlist the cooperation of Regional Groupings" in implementing a sanctions regime (art. i). Yet, 
the relationship between the $\mathrm{AU}$ and the sub-regional organizations regarding the maintenance of peace and security remains ambiguous when it comes to the division of labour and leadership.

For the purpose of the current dissertation, which examines instances of UCG in the West African region, only ECOWAS is examined.

\subsubsection{Economic Community of West African States (ECOWAS)}

The Economic Community of West African States was established in 1975 to promote economic cooperation and integration in the sub-region. The initiative was mainly led by Nigeria and Togo in recognition of the developmental potentials of regional approach to development. Following the withdrawal of Mauritania in 1999, the sub-regional organization currently counts fifteen member countries (Oloruntoba, 2016, p. 295). ECOWAS is located in Abuja, Nigeria.

The Treaty of Lagos lays the foundation for the establishment of ECOWAS; it was revised in 1993 to include issues of political concerns such as promotion of democracy and good governance, and maintenance of peace and security. Particularly, the inaction of the international community to respond to the civil wars in Liberia and Sierra Leone led countries to take action, resulting in the creation of the ECOWAS Monitoring Group (ECOMOG) (Oloruntaba, 2016, p. 298). In 2001, it was agreed that sanctions would be applied in cases of "abrupt end to democracy" or "massive violation of human rights in a Member state" (Protocol on Democracy and Good Governance, art. 45(1)). This function with regards to UCGs, and in tandem with the AU, is further explained in Chapter four. 
Since its inception, ECOWAS has been facing important challenges, including lack of economic structure, political organization, civil society involvement and resources for project management. In addition, the historical context of economic exploitation by European-led mercantilism, and current context of neoliberal global economic trade, leave little to no room for trade relations among ECOWAS' member states, namely due to their dependency on more developed countries. The influence of external forces, as well as ethnic and cultural divisions are other important factors.

Nevertheless, the sub-region has contributed to the stability of the West African region through conflict resolution and the promotion of democratic governance. It has made important progress at the political and institutional levels, namely through the creation of its Parliament, Bank of Investment and development and Court of Justice, although the latter lacks capacity for enforcement. The increasing presence of non-state actors in the region such as banks, telecommunication companies and civil society organizations also presents new possibilities for the future (Oloruntaba, 2016, p. 302).

\subsection{Conclusion}

This chapter has outlined the structure and mandate of the African Union. Reference was made to its predecessor, the Organization for African Unity, and reasons were given to explain its evolution to the AU as it is known today. The different organs and institutions of the $\mathrm{AU}$ were presented, along with their potential role in implementing sanctions regime in instances of UCG on the continent. Research indicates that the AU has shown progress and proactiveness in addressing the political and institutional challenges it is facing. However, the organization currently has no mechanism in place to 
monitor and ensure the implementation of its norm on UCG, nor does it (or any of its organs) have the authority to do so. A similar conclusion was also reached for the West African region, through the examination of ECOWAS.

Despite these limitations, the study offered in this chapter suggests that the AU and RECs play an important role in conflict resolution and the promotion of democratic governance. The next chapter looks more closely at this role by defining the AU's framework on UCG, with emphasis on sanctions. 


\section{Chapter 4: Responding to UCGs in Africa through sanctions}

This chapter looks at the African Union's framework regarding unconstitutional changes of government. The first section provides the definition of UCG as outlined within the framework. The second section examines the legal instruments regulating the AU's response to UCGs, focusing on their respective legal status. The third section informs on the Union's various organs involved in responding to UCG, notably their role and obligations, with emphasis on sanctions application. This will be done through an outline of the African Peace and Security Architecture introduced in the previous chapter. The fourth section reviews the sanctions regime, focusing on the decision-making process and types of sanctions imposed, in accordance with the related legal instruments.

\subsection{Defining unconstitutional changes of government within the AU framework}

Both the definition of the concept of unconstitutional change of government (UCG), as well as the African Union's most detailed policy actions are embedded in three main policy instruments: the 2000 Lomé Declaration on the Framework for an OAU Response to Unconstitutional Changes of Government (the Lomé Declaration), the 2007 African Charter on Democracy, Elections and Governance (commonly referred as the Addis Ababa Charter) and the Constitutive Act of the African Union of 2001. The Lomé Declaration considers four main situations as constituting instances of UCG:

- Military coup d'état against a democratically elected government;

- Intervention by mercenaries to replace a democratically elected government;

- Replacement of democratically elected governments by armed dissident groups and rebel movements; 
- The refusal by an incumbent government to relinquish power to the winning political party after free, fair and regular elections.

In addition, through the Addis Ababa Charter of 2007, the AU altered the OAU definition of UCG to also include:

Any amendment or revision of the constitution or legal instruments, which is an infringement on the principles of democratic change of government. (art. 23(5))

The Charter further expands the measures to be taken in the event of UCG and strengthens the AU's sanctions regime.

Lastly, the Malabo Protocol on the Amendments to the Protocol creating the African Court of Justice and Human Rights, adopted in 2014, added a last category:

Any substantial modification to the electoral laws in the last six (6) months before the elections without the consent of the majority of the political actors. (pp. 25-26)

Since its entry into force in 2012, the Addis Ababa Charter has been ratified by 30 of the 54 AU's member states. While the Charter is only applicable to members that have ratified it, the 2010 Decision foreseeing punitive measures against perpetrators of UCG adopted by the AU Assembly is generally applicable to all member states. Its adoption has thus engendered a so-called 'zero-tolerance' policy towards UCG (Zamfir, 2017). 


\subsubsection{Classification of unconstitutional changes of government}

From the above, two major forms of UCGs are discernable: the classical ones, which include the first three instances aforementioned; and the soft ones, which encompass the remaining three. The first category usually involves the use of force of violence to overthrow a legitimate and democratic government, with the most frequent form being the military putsch or coup d'état. Alternatively, the second category "consists of some practices that are apparently legal but which are devised to ensure continuity in the governance architecture through political manipulation of the fundamental legal provisions pertinent to accession to power" (Manirakiza, 2016, p. 9192). This particular form of UCGs presents significant legal challenges since there is nothing inherently illegal in making constitutional amendments and because neither AU law nor international law forbids long-term tenure in office following regular, fair and transparent elections (Manirakiza, 2016, p. 94). With military coups being decreasingly preferred due to the AU's tough stance against them, new soft means of UCGs which do not implicate, at least directly, violence or the use of force, have become a commonplace in Africa. If not properly addressed, this practice will most likely remain common in the future, thus seriously undermining democratic gains on the continent.

The current dissertation looks at instances of UCG which have resulted in sanctions imposition by the AU, with particular the first (military coup d'état against a democratically elected government), fifth (any amendment or revision of the constitution or legal instruments, which is an infringement on the principles of democratic change of government), instances of UCG. 


\subsection{The AU documents on UCG}

The transition from the OAU to the AU saw the adoption of a number of decisions and protocols for the promotion and maintenance of peace, democracy and good governance. Some of these instruments address in particular the question of UCG and are thus part of the AU's overall framework on the matter. The following section outlines the main frameworks and mechanisms regulating the AU's response to UCG. Exempt from the analysis are the Declaration on Observing and Monitoring Elections (2002) and the Declaration Governing Democratic Elections in Africa (2002). While recognizing the importance of fair and transparent elections in the democratic and electoral processes in Africa, this dissertation focuses solely on the role of sanctions in ensuring such processes.

\subsubsection{The Lomé Declaration on the Framework for an OAU Response to Unconstitutional Changes of Government}

The Lomé Declaration was adopted in 2000 by the OAU Member states, following a resurgence of unconstitutional changes of government on the continent. While not legally binding, the declaration is still politically accepted within the AU framework and often referred to during the decision-making process of sanctions application. Among other things, the Lomé Declaration promotes the importance of peace and credible elections and encourages constitutional means of accession to power (Nkosi, 2013, p. 17). It further denounces coups as "unacceptable and anachronistic" and "in contradiction of [the] commitment to promote democratic principles and condition", outlining the "role of the principles of good governance, transparency and human rights in building representative and stable governments as well as promoting democracy and 
democratic institutions in Africa" (Lomé Declaration). Notably, the importance of peaceful and credible elections is identified as a crucial factor in establishing the legitimacy of a government (Sithole, 2018, p. 70). The Lomé Declaration also outlines a set of instances which constitute UCGs, as well as guidelines regarding the AU's response to them. These guidelines are further explained in the fourth section of this chapter.

\subsubsection{The Constitutive Act of the African Union}

As previously discussed, the Constitutive Act of the African Union is the fundamental instrument of the organization. Drawing lessons from the OAU, the Constitutive Act sets the founding principles of the Union for the "promotion of democratic principles and institutions, popular participation and good governance" (art. $3 g)$. Such principles include the "condemnation and rejection of unconstitutional changes of governments" (art. $4 \mathrm{p})$. In this regard, the AU reserves the right to reject governments that come to power through unconstitutional means. Specifically, Article 30 stipulates that "governments which shall come to power through unconstitutional means shall not be allowed to participate in the activities of the Union. More importantly, article 23(2) provides the basis for sanctions imposition:

Furthermore, any Member State that fails to comply with the decisions and policies of the Union may be subjected to other sanctions, such as the denial of transport and communications links with other Member States, and other measures of a political and economic nature to be determined by the Assembly. 
Unconstitutional changes of government are the only commitment in the Constitutive Act backed by sanctions.

\subsubsection{The African Charter on Democracy, Elections and Governance}

Inspired by the principles and objectives outlined in the Constitutive Act of the AU, the African Charter on Democracy, Elections and Governance (ACEG) was adopted in Addis Ababa in 2007 and came into force in February 2012. The Charter "brought the desire to augment the AU's earlier declarations and decisions about peace and security on unconstitutional changes of government" (Sithole, 2018, p. 74) by prescribing the best practices for election management on the continent. Of important to this dissertation, article 23(4) identifies the refusal by an incumbent to relinquish power to the winning party as an unconstitutional change of government. In many ways, the Charter is a response to a new practice of amending constitutions in order to prolong the tenure of incumbent regimes beyond the prescribed term. Article 10(3) requires that such amendments should enjoy the support of the general population. However, "to date, none of the attempts to amend the constitution have been subjected to the will of the people in an unfettered and transparent manner" (Dube, 2010, p. 51). Article 25 of the Charter further allows the implementation of sanctions against perpetrators of unconstitutional changes of government.

Despite its supposedly binding nature, the reluctance of member states to fully commit to the Charter has been a major obstacle in its implementation. The continuing trend of constitutional revisions which allow African leaders to extend their stay in power evidences this reality. 


\subsubsection{The Ezulwini Framework for the Enhancement of the Implementation of Measures of the African Union in Situations of Unconstitutional Changes of Government in Africa}

The main objective of the 2009 Ezulwini Framework is to enhance "the effectiveness of the legal framework in the implementation of AU Instruments against unconstitutional changes of Government in Africa". It takes a zero-tolerance policy stance on coups and provides, among other measures, the imposition of sanctions in such instances.

The Ezulwini Framework is seen as progressive in that it addresses some of the shortcomings of the previous instruments, emphasizing on cooperation between the different organs involved in the African Peace and Security Architecture, as well as international partners. The Chairperson of the African Union Commission is tasked with overseeing the implementation of the framework.

Yet, despite the progressive nature of the Ezulwini Framework, the document presents limitations in its implementation which are revealed in the analysis of the case studies.

The recommendations provided in the conclusion of this dissertation relate to the improvement of the framework.

\subsection{The African Peace and Security Architecture}

The African Peace and Security Architecture (APSA) was established in the context of the transformation of the OAU into the AU in the 2000s. The transition was in part fueled by important developments on the continent following the end of the Cold War. The current structure of the APSA is based on the principle of conflict prevention 
and resolution through partnerships with Regional Economic Communities (RECs) and their Regional Mechanisms (RMs).

APSA is the primary institutional mechanism that deals with conflict on the continent and includes three central instruments for conflict prevention, conflict management and peace building: the African Union, RECs and RMs. The normative and institutional foundations of the APSA include the African Union Constitutive Act, the Protocol on the Establishment of the Peace and Security Council of the African Union (PSC Protocol) and the Solemn Declaration on the Common African Defence and Security Policy ${ }^{9}$, all of whom include a firm commitment to democracy and good governance (Desmidt, 2016, p. 4). The PSC Protocol further outlines the various components of the APSA, as well as their respective responsibilities.

The APSA consists of five pillars: the Panel of the Wise (POW), the Continental Early Warning System (CEWS), the Peace Fund (AUPF), African Standby Force (ASF), and the Peace and Security Council (PSC). Also included is the African Standby Force, which is raised and maintained by the the RECs/RMs.

${ }^{9}$ The Common African Defence and Security Policy (CADSP) was adopted in February 2004 in Sirte, Libya. The CADSP goes beyond the AU's focus on peacekeeping by seeking to deal with conflicts both directly and indirectly through preventive diplomacy and rapid interventions in conflict zones. Together with the New Partnership for African Development (NEPAD), the Common African Defence and Security Policy emphasizes the role of development as a necessary condition for peace and stability. The CADSP and NEPAD constitute an important part of the continental-wide regime on peace and security, and reiterate some of the Constitutive Act's main principles, namely the condemnation of UCGs. For the purpose of this dissertation, they are not examined in depth. 


\section{Illustration 2 Pillars of the African Peace and Security Architecture}

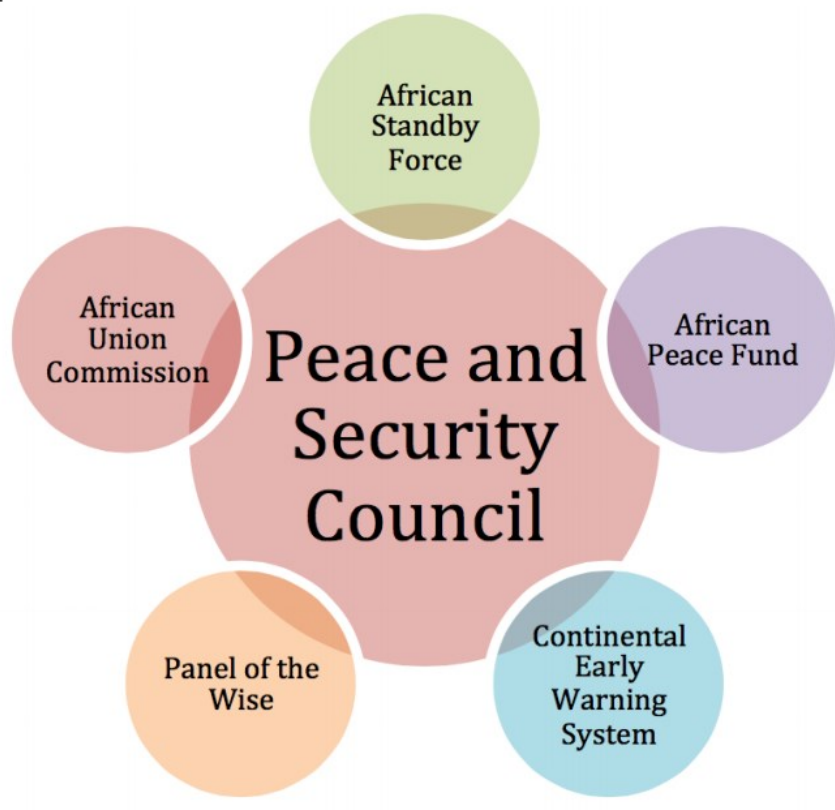

Source: Desmidt, S. (2016). Peacebuilding, conflict prevention and conflict monitoring in the African Peace and Security Architecture. European Centre for Development Policy Management, 1-16.

\subsubsection{The Peace and Security Council}

The Peace and Security Council acts as the main pillar of the APSA. It provides early warning on conflicts and ensures collective security. The PSC is also tasked with "facilitating timely and effective response to conflict and crisis situations in Africa; preventing, managing and resolving conflicts; building post-conflict peace; and developing common defense policies" (Protocol Relating to the Establishment of the Peace and Security Council of the African Union). Its structure and functions are outlined in more depth in the third chapter of this dissertation.

\subsubsection{Continental Early Warning System}

The Continental Early Warning System provides timely advice on potential threats to peace and security to the AU Commission Chairperson, to be brought to 
attention of the PSC. This is done through the collection and analysis of data by an observation and monitoring Centre, in conjunction with similar structures in the RECs, including ECOWAS.

Yet, the CEWS remains restricted by human resource limitations; underdeveloped cooperation and information sharing with the early warning efforts of regional organizations; unsystematic coordination with the various AU organs focusing on peace and security; and issues of political will (Noyes \& Yarwood, 2013, p. 1).

\subsubsection{Panel of the Wise}

The Panel of the Wise consists of five prominent personalities (representing the five regions of Africa) who have made "outstanding contributions to the cause of peace, security and development on the continent" (AU Commission's Peace and Security Department, 2018). The Panel is responsible for providing the PSC advice on the prevention, management and resolution of conflicts. Occasionally, it may act on request or may take all initiatives deemed necessary to support the efforts of the PSC and the AU Commission Chairperson, including "conducting on-the-ground fact-finding, presenting policy options, and brokering [peace] agreements" (Nantulya, 2016). To achieve these ends, the Panel of the Wise relies heavily on sub-regional entities, such as ECOWAS' own Council of the Wise, which assumes a similar role at the regional level.

\subsubsection{African Union Commission}

As previously outlined, the Chairperson of the African Union Commission is responsible for the implementation of PSC decisions, for informing the Council on its 
activities and for issuing periodic reports and documentation. The Chairperson is assisted by the AU Commissioner for Peace and Security.

\subsubsection{African Peace Fund}

The African Peace Fund provides necessary funding and resources for operational activities related to peace and security, including peace support missions. Its budget is made of contributions from the AU's overall budget, as well as voluntary contributions from African and international donors.

As previously discussed, the Fund has long been inadequately funded, with African States comprising only 2\% of the budget from 2008 to 2011, and international donors being the main contributors (Karock, 2014, p. 6).

\subsubsection{The African Standby Force}

The African Standby Force (ASF) is the African peacekeeping force composed of military, police and civilian contingents. It is usually deployed in crisis situations and is authorized to participate in peace support missions.

The 2003 ASF Policy Framework foresaw the creation of brigade-sized regional standby forces, established by the RECs; however, this has yet to be achieved (Karock, 2014, p. 7). 


\subsection{The application of sanctions}

Together with the legal documents previously presented, the Rules of Procedure of the Assembly, as well as the PSC Protocol are important to consider when looking at the role and responsibilities of AU organs in cases of UCG.

On one hand, the PSC Protocol specifies that the Peace and Security Council shall institute sanctions in cases of UCG, as provided by the Lomé Declaration, although it does not define the sanctions more clearly. On the other, the Rules of Procedures of the Assembly determine the conditions of application as well as the types of sanctions imposed.

The Lomé Declaration sets out four steps in the AU's response to UCGs through sanctions. First, the Chairperson of the AU Commission publicly condemns the unconstitutional change of government, calling for a return to constitutional order. A meeting is then held by the PSC to discuss the situation as a matter of 'urgency'. The AU subsequently suspends the perpetrator from participating in AU activities for a period of six months, until constitutional rule is reinstated. During that period, AU member states, together with the Chair of the AU Commission and, in cooperation with RECs, continuously engage with the unconstitutional government through diplomatic means to restore democratic rule. If all these options fail within the six-month suspension period, the AU Assembly may then decide to impose targeted sanctions, upon request from the Executive Council and in accordance with Rule 36 of the Rules of Procedure of the Assembly. Alternatively, the Assembly may initiate the process by making a suggestion to the Agenda. The PSC is responsible for enforcing the sanctions, with the support of member states, regional blocs and international partners (Souaré, 2009). Furthermore, 
article 7(g) of the PSC Protocol stipulates that it shall impose sanctions in conjunction with the Chairperson of the Commission. The AU Commission is tasked with ensuring the enforcement of the AU decisions regarding UCG, although the Protocol does not clearly outline how this task should be performed.

Chapter 10 of the Addis Charter provides the mechanism for sanctions application, including the roles of individual states, organs and RECs.

\subsubsection{Types of sanctions applied}

Both the Lomé Declaration and Rules of Procedure of the Assembly prescribe the same sanctions in the event of unconstitutional changes of government. These include visa denials for the perpetrators of UCGs, restriction of government-to-government relations, as well as trade restrictions. These measures were later reaffirmed by the African Charter on Democracy, Elections and Governance (Addis Charter), which prescribes other negative material incentives targeting the whole country, with the assumption that such measures may prompt the unconstitutional government to restore democratic rule. The Addis Charter also introduces more targeted sanctions, namely making perpetrators of UCGs face an AU court and prohibiting member states from granting them asylum.

\subsubsection{Sanctions' application in practice: successes and failures}

Since its creation in 2001, the AU has systematically condemned UCG and applied sanctions to the following states: 
Table 1 Cases of UCG resulting in sanctions application by the African Union

\begin{tabular}{|c|c|c|}
\hline COUNTRY & YEAR & $\begin{array}{l}\text { RESPONSE/ TYPE OF } \\
\text { SANCTIONS }\end{array}$ \\
\hline Comoros & 2001 & AU membership suspension \\
\hline Madagascar & 2001 & $\begin{array}{l}\text { AU membership suspension } \\
\text { AU membership suspension, } \\
\text { travel bans }\end{array}$ \\
\hline Guinea & $\begin{array}{l}2001 \\
2008\end{array}$ & $\begin{array}{l}\text { AU membership suspension } \\
\text { AU membership suspension, } \\
\text { travel bans, asset freezes }\end{array}$ \\
\hline Central African Republic & $\begin{array}{l}2001 \\
2003 \\
2013\end{array}$ & $\begin{array}{l}\text { AU membership suspension } \\
\text { AU membership suspension } \\
\text { AU membership suspension, } \\
\text { travel bans, asset freezes }\end{array}$ \\
\hline Togo & 2005 & AU membership suspension \\
\hline Mauritania & 2005 & $\begin{array}{l}\text { AU membership suspension } \\
\text { Visa restrictions, travel bans, } \\
\text { asset freezes }\end{array}$ \\
\hline Comoros & 2007 & $\begin{array}{l}\text { Travel bans, asset freezes; AU } \\
\text { military intervention }\end{array}$ \\
\hline Côte d'Ivoire & 2010 & AU membership suspension \\
\hline Mali & 2012 & $\begin{array}{l}\text { AU membership suspension, } \\
\text { travel bans, asset freezes }\end{array}$ \\
\hline Guinea-Bissau & 2012 & AU membership suspension \\
\hline Egypt & 2013 & AU membership suspension \\
\hline
\end{tabular}

Source: Manirakiza, P. (2016). Insecurity implications of unconstitutional changes of government in Africa: from military to constitutional coups, p. 98 
Despite the growing crisis of governance across Africa, the AU has shown both strengths and weaknesses in its response to UCG. While it has done well in creating and developing normative instruments to promote and protect democracy, good governance, rule of law and human rights, the Union still struggles with implementing these norms with consistency and coherence (Aniekwe, 2015). Among the major issues that arise is the lack of political will by and amongst AU member states who are "often divided over how to respond to Africa's conflicts" (Sithole, 2018, p. 82). Additionally, there seems to be tension between application of both the norm of non-indifference - the right to intervene in a member state in respect of war crimes, genocides and crimes against humanity - and the principle of non-intervention, resulting in a "diplomatic egg-dance around questions of sovereignty and consent" (Engel \& Porto, 2009, p. 91). The lack of resources, both financial and material, has also been an obstacle to the functioning of the framework. Finally, as mentioned previously, the reluctance of the African leaders to fully commit to the framework's normative instruments, namely the Charter, has significantly affected its enforcement mechanism (Sithole, 2018, p. 84).

Today, sanctions remain the most far reaching measure in the AU framework of response against UCG, and theoretically the UCG framework of the AU reflects its commitment to ensuring democratic governance. However, both successes and failures characterize the $\mathrm{AU}$ in its quest to fulfill its mandate, which will require cooperation and coordination at all levels of governance. 


\subsubsection{The role of sub-regional actors}

Among the regional and sub-regional actors involved in peace and security maintenance, only ECOWAS has developed a peace and security architecture which aligns itself with the AU sanction policy. As a result, it is generally viewed as the most capable of the sub-regional entities.

The ECOWAS Protocol on Democracy and Good Governance was adopted in 2001 as an attempt to deter and prevent military coups and UCGs in the region. The Protocol contains a 'trigger mechanism' that automatically suspends states from ECOWAS, in the event of an unconstitutional change of government, together with other constitutional and legal provisions. Lesser sanctions are also outlined, such as the refusal to support candidates for elective posts in international organizations, as well as to host ECOWAS meetings within the unconstitutional government's state (Cowell, 2011, p. $331)$.

Out of the fifteen states in sub-regional organization, only two have never been subject to a military coup or a UCG. Furthermore, since 1990, ECOWAS has applied a total of eight sanctions against seven of its members, all of which were in response to UCGs (Cowell, 2011, p. 331).

\subsection{Conclusion}

This chapter offered an overview of the African Union's frameworks and mechanisms in place to respond to unconstitutional changes of government. A definition and classification of UCGs was first provided, outlining the similarities and differences 
among the various AU legal instruments defining the concept. Six instances of UCGs were nevertheless identified; the dissertation focuses on two of them.

A study of the main legal documents embedded in the AU framework on UCG revealed limitations in the Union's enforcement mechanism. Moreover, the examination of the African Peace and Security Architecture, introduced in the previous chapter, suggests that the AU's policy against UCGs is relatively well defined. However, an overview of the sanctions regime, as prescribed by the AU framework, shows both theoretical and conceptual flaws. Lastly, research indicates a willingness from the AU and RECs to develop shared model developments to address conflict on the continent, although coordination remains limited.

The subsequent chapter examines the aforementioned conclusions through case studies of UCGs in the West African region. In doing so, it seeks to identify strengths, weaknesses, patterns and means of improvement in the AU response. 


\section{Chapter 5: Case studies}

This chapter looks at three case studies of UCG that have prompted the AU to apply sanctions. While these cases have all resulted in a return to democratic and constitutional order, they each hold particularities which will help outline characteristics of the AU's practical framework on UCG.

The countries that will be studied are Togo (2005), Mauritania (2008) and Mali (2012). In particular, the circumstances leading to the UCG will be given (context), the response, including the actors involved and measures taken, will be identified (response), and the outcome of the case will be given (outcome).

In light of the presentation, brief thoughts will be given in the conclusion regarding the AU's stance on UCGs and the role of ECOWAS in that regard.

\subsection{Selection of case studies}

The selection for this dissertation was made from a compilation of unconstitutional changes of government that has taken place in Africa since the AU was founded in $2001 .^{10}$ Case studies were selected based on a series of criteria and restrictions.

First, the three case studies occurred after 2004, following the first meeting of the Peace and Security Council. The PSC was among the last AU institution to be

\footnotetext{
${ }^{10}$ This compilation can be found in Table 1 titled "Cases of UCG resulting in sanctions application by the African Union", presented in the previous chapter.
} 
established; hence, it can be assumed that focusing on the post-2004 period would ensure an accurate assessment of the Union framework on UCG, namely the African Peace and Security Architecture, which would have been implemented and functional by then. Moreover, the cases span almost a decade which allows for an evolutive analysis of the AU's response through time. The availability of information, both in the media and literature, also influenced the choices of the case studies. Consequently, this chapter relies significantly on secondary sources.

Additionally, the countries examined are all situated in the West African subregion. West Africa is of particular interest to this research because it has a long history of coups d'état, in spite of having had its colonization era end relatively early and smoothly compared to other parts of the continent. While it is not possible to consider West African states as a whole, since they experience different dilemmas caused by internal and external complexities, they still present common threads which can be helpful in understanding the AU's response mechanisms (here, sanctions) to political movements and shifting power dynamics in the region, as well as how such responses can be improved.

Finally, the dissertation is aware that all case studies have resulted in the restoration of democratic and constitutional order. This outcome was not done intentionally, but resulted from the aforementioned criteria and restrictions present during the selection process. This will be taken into consideration in the discussion. 


\subsection{Togo (2005)}

\subsubsection{Context}

General Gnassingbé Eyadéma came to power in a coup in 1967. After introducing a multiparty constitution in 1992, he secured the office in 1993, 1998 and 2003 in widely contested elections. He died on February 5, 2005, after thirty-eight years in power.

The 1992 Constitution had prescribed for the President of the National Assembly (Fambaré Natchaba Outtara) to succeed to him for an interim period not exceeding sixty days, during which elections would be held. However, Eyadéma's son, Faure Gnassingbé, was installed as President in a military coup by the Togolese Armed Forces. The Togolese army justified the coup on the grounds that Outtara was out of the country when in fact, he had been prevented from returning by the army who had closed all of Togo’s borders (Omorogbe, 2011, p. 139).

On February 2005, the National Assembly, which was dominated by members of the ruling Togolese People party, voted to appoint Faure Gnassingbé as its President, thus removing Ouattara. In an attempt to further legitimize the move, the Assembly amended the Constitution "to allow the new President to continue in office without organizing an election until the end of the mandate of Gnassingbé Eyadéma in 2008” (Omorogbe, 2011, p. 139). In doing so, the National Assembly violated the fundamental law by ignoring the constitutional provision which stated that no revision procedure may be initiated or continued during an interim period (Banjo, 2008, p. 152). 


\subsubsection{Response}

Togo had ratified the PSC Protocol in February 2004. As such, the PSC was in a position to respond to the coup.

On February 7, 2005, the Nigerian head of State and chairman of the AU, then President Olusegun Obasanjo, together with the Chair of the AU Commission, Mali's former president Alpha Oumar Konare, condemned both the military coup and the "constitutional modifications intended to legally window dress the coup d'état" (AU Peace and Security Council, 2005). Obasanjo further called for constitutional order and threatened to impose sanctions, as prescribed by Article 7(g) of the PSC Protocol and the Lomé Declaration. International actors, including the British Foreign and Commonwealth Office, former colonial ruler France, the United States and La Francophonie, also called for democratic/constitutional power transfer in Togo, with the latter instantly suspending the country (Banjo, 2008, p. 152-153).

On February 9, 2005 and in conjunction with ECOWAS, the PSC reiterated its message, demanding that the succession be conducted according to the pre-amended Constitution.

Ten days later, ECOWAS, under the leadership of its then chairman and former Nigerien president, Mamadou Tandja, imposed sanctions in the form of an arms embargo and a travel ban on Togolese leaders.

On February 18, the Togolese National Assembly restored the constitutional provisions which required elections to be held within sixty days, but kept Faure Gnassingbé as President of Togo for the interim period. 
As a result, the AU suspended Togo from AU activities until the restoration of constitutional order. Specifically, the Union rejected "any election that would be organized under the conditions enunciated by the de facto authorities in Togo," required the resignation of Faure Gnassingbé, and endorsed ECOWAS' sanctions. Additionally, the AU instructed ECOWAS to "take all such measures as it deem[ed] necessary to restore constitutional legality in Togo within the shortest time" (AU Peace and Security Council, 2005).

\subsubsection{Outcome}

In addition to public condemnation, and in accordance with rule 37 (6) of the Rules of Procedure of the Assembly of the Union, ECOWAS appointed Nigeria, Niger, Benin, Ghana and Mali to meet with a Togolese delegation in Niamey. However, the Togolese authorities chose not to cooperate by refusing to grant landing rights to the plane carrying the ECOWAS delegation (Banjo, 2008, p. 157).

Ultimately, Faure Gnassingbé resigned as President of Togo on February 25, 2005, following pressure from the AU, ECOWAS and the international community. He handed power of the interim administration to Abass Bonfoh - previously Vice-President of the National Assembly - who became President of the National Assembly and acting President of Togo. ECOWAS considered the decision to constitute a full return to constitutional order and lifted its sanctions the following day, but the AU did not.

On April 24, 2005, Faure Gnassingbé was elected president in elections widely contested by the opposition, the Union des Forces du changement (UFC), as well as by 
international observers (European Parliament, 2005). Despite the irregularities observed, the Constitutional Court of Togo, ECOWAS and the AU accepted the result. The dispute over the elections led to widespread violence across Togo, where "several hundred people died, thousands were wounded, 15,000-16,00 were internally displaced and 40,000 fled to neighboring states" (Omorogbe, 2011, p. 141). Yet, the AU considered that the technical conditions set for a restoration of constitutional order had been met and on May, 27 2005, the PSC lifted its ban, allowing Togo to partake in AU activities (AU Peace and Security Council, 2005).

Despite the resolution, Togo continues to be politically unstable. Following Faure Gnassingbé's second presidential win on March 4, 2010, the elections were once again disputed domestically. Yet, neither AU nor ECOWAS condemned the result, leading protestors to take to the streets (Banjo, 2008, p. 159). In an attempt to diffuse the situation, the government and the leader of the UFC formed a coalition on May 28, 2010. However, the coalition has proven unpopular with the majority of UFC members who have continued to question the legitimacy of Faure Gnassingbé's election (Omorogbe, 2011, p. 141-142). As of 2018, Faure Gnassingbé remains in power. Moreover, rather than marking the end of a succession crisis, the presidential elections' results signalled "the beginning of a low-level, non-violent battle of attrition over the soul nation politics in Togo" (Banjo, 2008, p. 160), more than 50 years into the Gnassingbé dynasty. 


\subsubsection{Conclusion}

Overall, the Togo case showed the AU, in cooperation with ECOWAS, refusing to accept a civilian government that came to power through a military coup. By coordinating their actions, both institutions condemned the coup and followed the set guidelines in response, namely by imposing sanctions on the perpetrators. These efforts ultimately resulted in the restoration of constitutional order, before the end of the sixmonth suspension period. However, following Faure Gnassingbé's win during the two subsequent elections of 2005 and 2010, the AU and ECOWAS proved unwilling to condemn the contested results, even after uproar across the country spread. By doing so, the AU, together with ECOWAS, appear reluctant to "[condone] the election results and the associated brutal persecution of opponents [...] in the interest of political stability in the sub-region", managing to "temporarily [avoid] sliding into the level of chaos already seen in some other West African states with similar succession crisis, such as Côte d'Ivoire, Sierra Leone and Liberia" (Banjo, 2008, p. 159-160).

In many regards, the Togo case outcome presents similarities to that of Mauritania, the next case country in which the AU opposed a coup.

\subsection{Mauritania (2005 and 2008)}

\subsubsection{Context}

Following a military coup that took place in the Islamic Republic of Mauritania, President Maaouya Ould Sid'Ahmed Taya was deposed on August $3^{\text {rd }} 2005$ while attending the funeral of King Fahd in Saudi Arabia. At that time, Mauritania had had a 
history of military interference in state affairs since achieving independence from France in 1960, with Taya himself gaining power through a coup in December 1984 (Magliveras, 2011, p. 17). The new military regime promised to hold power for no more than two years, during which they would prepare genuine democratic institutions (Omorogbe, 2011, p. 142-143).

On August $4^{\text {th }} 2005$, the day following the coup, the PSC decided, in conformity with the Lomé Declaration and related principles of the Constitutive Act, to suspend Mauritania's participation in AU activities until the restoration of constitutional order. The suspension remained in place for several months, even after a number of actions were undertaken by the Mauritanian authorities starting September 2005 (Omorogbe, 2011, p. 142-143). These positive developments included making amendments to the Constitution limiting the powers of the President and setting a rule limit of two five-year terms (Mauritanian Constitution, 2006).

A pledge from Mauritania's military leaders to hold presidential elections in March 2007 eventually led to the election of President Sidi Mohamed Ould Cheikh Abdallahi, following successful and democratic elections. Following the elections, Mauritania`s membership to the AU was restored.

On August 6, 2008, the Presidential Guard arrested the President Sidi Mohamed Ould Cheikh Abdallahi, the Prime Minister, and the Minister of the Interiors, on grounds of corruption. The coup came a few hours after the top four military officers, including General Abdel Aziz, were removed from their positions through a presidential decree (Omorogbe, 2011, p. 144). An official statement was issued informing the general public that Abdallahi was stripped of his powers, and that the country shall hereby be governed 
transitionally by an 11-member High Council of State headed by Aziz, until new free and transparent presidential elections were held. The majority of the members of Parliament supported the coup (Omorogbe, 2011, p. 144).

\subsubsection{Response}

The PSC immediately condemned the military coup, demanding the release of those who had been arrested, as well as the restoration of constitutional order and of the institutions democratically chosen by the population in 2006-2007 (Omorogbe, 2011, p. 144). Furthermore, the PSC stated in a communiqué that it stressed the relevant provisions of the Constitutive Act, Lomé Declaration, the PSC Protocol and the African Charter on Democracy, elections and governance, which "provide in particular for the automatic suspension of the participation of the country concerned in the activities of the AU until the restoration of constitutional order" (AU Peace and Security Council, 2008). Ironically, Mauritania had ratified the Addis Charter just a month before the coup occurred, which enabled the Union to suspend the country from its activities on August 9. Moreover, and pursuant to rule 37 (6) of the Rules of Procedure, as well as article 7 and 10 of the PSC Protocol, the Peace and Security Commissioner was also sent to engage in negotiations with the coup leaders.

In a Presidential Statement dated August 19, 2008, the UN Security Council further condemned the Mauritanian coup, demanding the release of President Abdallahi and the restoration of constitutional order (UN Security Council, 2008).

In late September 2008, the PSC met again to discuss, among others, the situation in Mauritania. While noting that no real progress had been made towards a possible 
resolution, the PSC did observe that Mauritania had become the first Member State to adhere to the African Charter on Democracy, Elections and Governance on July 7, 2008, although the Charter had yet to enter into force. Still, the PSC warned the country it would face "sanctions and isolation" (AU Peace and Security Council, 2008) if President Abdallahi was not restored in power by October 6, 2008, and declared null "all measures of constitutional, institutional and legislative nature which were adopted by the military authorities following the 2008 coup" (Magliveras, 2011, p. 19).

A month after the deadline passed, the PSC concluded, during its $156^{\text {th }}$ Meeting that no concrete steps had been taken to restore democracy, despite statements of condemnation by other international bodies such as the European Union, the United Nations and the League of Arab States. Additionally, the PSC requested that the AU Commission proposed concrete measures to put in place to address the situation, in accordance to the Lomé Declaration (AU Peace and Security Council, 2008). In response, the Commission recommended that the PSC should consider imposing (targeted) sanctions if no progress had been done by January 2009. These sanctions included: denying visas, imposing travel restrictions and freezing assets of all those whose international travels were intended to maintain the unconstitutional status quo (AU Assembly of Heads of States, 2009). Lastly, the Commission suggested that the UN Security Council (UNSC) consider imposing similar sanctions "to impart them a universal character" (AU Commission, 2008).

The PSC espoused the Commission's recommendations but decided it would impose sanctions by February 5, 2009 if constitutional order was not restored. By then, President Abdallahi had been released and the PSC felt this only partially responded to 
demands made by the international community. The PSC also informed the UNSC of its decision, hoping that it would confer a universal character to the proposed measures (AU Peace and Security Council, 2009).

On February 5, 2009, the day the ultimatum ended, along with the six months suspension period prescribed by the Lomé Declaration, the Union imposed economic sanctions on members of the junta and their supporters in the form of visa and travel bans, as well as assets freezes. However, the PSC also pointed that efforts should be made by the AU, its partners and the Mauritanian parties to ensure a return to constitutional order (AU Peace and Security Council, 2009).

\subsubsection{Outcome}

In June 2009, a solution was reached between the parties in Mauritania, with assistance from third parties, including then Senegalese President Abdoulaye Wade and Libyan leader Muammar Gaddafi, who was Chairman of the AU at the time ("Mauritania: Parties Agree on Interim Govt, Election Date," 2009). The negotiation process culminated in the Dakar Framework Agreement, whose prescribed measures included "the formation of a national transitional unity government; the transformation of the High Council of States into a defence organ subordinate to the authority of the government; the decision of President Abdallahi to hand in his mandate to the Mauritanian people; and that the President of the Senate take over as acting President of the Islamic Republic of Mauritania” (Magliveras, 2011, p. 21).

On June 19, 2009, the PSC declared that the country had returned to constitutional order and lifted its sanctions. With upcoming elections scheduled for July 2009, the PSC 
declared that it was monitoring the situation and that it was prepared to re-impose sanctions if warranted (Magliveras, 2011, p. 21).

The July 2009 elections saw Mohamed Ould Abdel Aziz, who had orchestrated the 2005 and 2008 coups, become President with 52\% of the vote. He remains in office at the time of the writing.

\subsubsection{Conclusion}

In the case of Mauritania, the PSC appeared to rely heavily on multilateral partners, including international organizations and foreign countries, to resolve the matter. The PSC also showed reluctance to impose sanctions against unconstitutional authorities without support from sub-regional organizations. It preferred instead to delay their imposition until after the six-month suspension period, against recommendation from the AU Commission. While the absence of involvement from ECOWAS could very well be explained by Mauritania's withdrawal from the organization in $2000,{ }^{11}$ it is interesting to note that no regional organizations seemed to have played any major roles in the conflict resolution.

The Mauritanian case also showcases the rising trend of using elections to validate the results of coups, prompting the $\mathrm{AU}$ "to [therefore] discourage the

\footnotetext{
${ }^{11}$ Mauritania withdrew at that time to concentrate on the implementation of the action plan of the Arab Maghreb Union (AN). In May 2017, Mauritania signed an agreement with ECOWAS aimed towards improving economic and security situation in the region, namely through common external tariff, trade liberalization scheme and free movements of goods, people and capitals. Later that year, the country showed interest in becoming a full member ECOWAS member. The first session of the ECOWASMauritanian integration council was held on October 27, 2017. However, as of 2018, no further developments have been made.
} 
beneficiaries of coups from standing in elections intended to restore constitutional government" (Omorogbe, 2011, p. 146).

Such disposition is prescribed by the Addis Charter, which states that "perpetrators of unconstitutional change of government shall not be allowed to participate in elections held to restore the democratic order or to hold any position of responsibility in political institutions of their State." However, as the Charter had not yet entered into force at the time of the Mauritanian case, the provision could not be enforced.

\subsection{Mali}

\subsubsection{Context}

On the night of March 21, 2012, a coup led by Captain Amadou Sanogo overthrew Amadou Toumani Touré's regime, forcing him into hiding. The military coup leaders cited the lack of support from the central government to their campaign against the Tuareg rebels in the North region as the main reason for their actions. At that time, Mali was coping with intermittent tensions between the minority Tuareg rebels and government forces. The conflict was aggravated by the 2011 Libya conflict and the unexpected fall of the Gaddafi regime. The return of Tuareg rebels to Mali brought much visibility to the rebellion, reaching the Movement of the National Liberation of Azawad and providing "an entry point for [newly-armed] splinter groups such as Al-Qaeda, Movement for Unity and Jihad and Ansar Dine to come to the fray" (Aning \& Edu-Afful, 2016, p. 128).

The perpetrators of the coup proclaimed the creation of the National Committee for the Re-establishment of Democracy and the Restoration of the State (CNRDRE). The 
CNRDRE also noted the climate of uncertainty surrounding the upcoming elections of April 2012 and the incapacity of the regime to fight terrorism (Hagberg \& Körling, 2012, p. 112).

As a result of the coup, Islamist extremist groups in the Northern region of the country profited from the political turmoil to further expand their operations and presence across the North territory, with detrimental humanitarian and cultural consequences for the population (Cristiani \& Fabiani, 2013).

\subsubsection{Response}

The coup was unanimously condemned by the international community, the AU and ECOWAS. The AU immediately suspended Mali from AU activities, in accordance with the Lomé Declaration and rule 37 (4) of the Lomé Declaration, while ECOWAS responded by initiating steps towards a political resolution of the conflict. Among other things, the sub-regional body condemned the coup, demanding for power to be given back to the legitimate government and for constitutional order to be restored (Okyere, Emmanuel Kwesi Aning \& Abdallah, 2012). ECOWAS also facilitated the outline of a roadmap to restore democracy and to reform the Malian army and threatened to impose sanctions.

Ultimately, with no progress achieved, the organization imposed economic and diplomatic sanctions on Mali in April 2012 (Aning \& Edu-Afful, 2016, p. 128). Additionally, former Burkinabe leader and ECOWAS President Blaise Compaoré was 
appointed to lead the political process of removing the military junta from power, as part of the provisions of rule 37 (6) of the Rules of Procedure of the Assembly of the Union.

ECOWAS also proposed the creation of a peace enforcement mission in Mali, the ECOWAS Mission in Mali (MICEMA) (Weiss \& Welz, 2014). Yet, despite both internal and international pressure to deploy military forces in the country, the AU favored diplomatic efforts.

On April $2^{\text {nd }}$, the AU introduced wider sanctions, including travel bans and freezing assets, to support ECOWAS' actions. These efforts were reinforced by the closing of borders and seaports by members of ECOWAS in an attempt to restrain the activities of the junta. In addition to support from the UNSC, the United States also joined in announcing a travel bans on the coup's leadership.

\subsubsection{Outcome}

On April 6, 2012, Sanogo and the CNRDRE, and ECOWAS signed a framework agreement prescribing for the return of civilian rule, under the mediation of Compaoré. As a result, Diouncounda Traoré, speaker of the National Assembly, was installed as interim President and Cheikh Modibo Diarra as Prime Minister. Both were presidential candidates for the upcoming elections (Hagberg \& Körling, 2012, p. 119).

The political transition sparked tension and outrage between the various Malian political factions, especially following the announcement of the new government. The division weakened the positions of the interim president and prime minister, and reinforced the position of Sanogo as the "real" head of state (Hagberg \& Körling, 2012, p. 119). 
Sanogo's reluctance to relinquish power led ECOWAS to hardened its stance, denouncing the CNRDRE as an obstacle to effective transition. Furthermore, at a meeting held on April 26, 2012 in Abidjan, it was convened that the transitional government would remain in place for 12 months, in preparation of the elections. While he initially contested the "unilateral" decision of ECOWAS, Sanogo eventually agreed to the terms (Hagberg \& Körling, 2012, p. 120).

In July 2012, ECOWAS grew unsatisfied with the political developments in Mali and called for the creation of a government of national unity. Formed on August 20, the new cabinet consisted of 31 ministers, five of which had known ties to Sanogo, the coup leader. Some of the minsters were chosen by the military, with others remaining unchanged from the previous government. None of the selected ministers had close links to the ousted, democratically elected President (Diallo, 2012).

According to the 1992 Constitution, elections were scheduled to take place in 2012, with the first round on April 29 and the second on May 13. A referendum was also planned during the first round to revise the Constitution. The elections would have marked the end of the second term of Amadou Toumani Touré, in conformity with the two-term limit prescribed by the Constitution. Toure had confirmed, in June 2011, that he would not stand in election again ("Communiqué du conseil des ministers du jeudi 27 décembre 2018," 2018).

Due to the coup and Tuareg insurgency in the North regions, the Malian presidential elections were finally pushed back to July 28, 2013, with a second run-off scheduled on August 11. The elections saw Ibrahim Boubacar Keïta, former Prime Minister and speaker of the National Assembly, become President with $77.61 \%$ of the 
vote during the second round. Days later, Sonogo was promoted to General. At the time of this writing, Keïta remains in office.

\subsubsection{Conclusion}

Mali provides interesting lessons regarding the role of sub-regional organizations and the impact of internal unrest on political matters. Seemingly, the 2012 military coup was born due to the government's poor handling of the Tuareg rebellion in the country's desert north, however, "the roots of dissatisfaction within the army and the security and defense forces run deeper than trauma from human loss and military setbacks" (Alozieuwa, 2013, p. 394), a topic which remains beyond the scope of the current dissertation. Yet, withstanding the imposition of sanctions, mounting pressures, both internal and external, appear to have played an important role in the relatively quick political resolution of the conflict.

If anything, the Malian case reveals the proactivity of ECOWAS and its members to instigate and coordinate a response to UCG, which includes the imposition of sanctions. In that regard, the role of the AU - and its international partners - remained quite minimal, which showcases the organization's reliance on its sub-regional counterparts. Also worth highlighting is the part that West African states and leaders played in the response, although the eventual deployment of the African-led International Support Mission to Mali in January 2013 will overshadow the initiatives undertaken by both the AU and ECOWAs in the resolution of the conflict. 


\subsection{Conclusion}

This chapter has discussed three case studies of UCG in three West African states, namely Togo (2005), Mauritania (2008) and Mali (2012). Specifically, the events leading to the UCG were outlined as background; the response of the AU, ECOWAS and their partners was examined; and the outcome of each case was laid out. Of importance to this dissertation is the prominent role that ECOWAS played in Togo and Mali, and the legitimacy bestowed upon it by the AU and international partners such as the UN and foreign countries.

An overview of the cases revealed that the AU and ECOWAS seem to follow relatively closely the guidelines set up by the UCG framework (immediate condemnation and warning; suspension from AU activities during which negotiation attempts are made with the assistance of RECs, African leaders and other partners and; implementation of targeted sanctions six months following the suspension), and that they tend to view sanctions as a "last minute" resort instrument. However, the cases also reveal discrepancies in the period between which the AU issues its warning against the UCG, and when it suspends the Member state from participating in its organs. Moreover, it is interesting to note that the Union did not respect the six-month suspension period in Mali as it did in Togo and Mauritania, deciding instead to impose targeted sanctions less than a month after the coup. This exception suggests that the AU may deflect from its policy depending on the nature, dimension and implications of the UCG. Although the circumstances surrounding each case were quite different, this dubious demur from the 
Union was also observed in the case of Zimbabwe (2017) which will be discussed in the next chapter.

While the case studies indicate that both institutions have adopted a zerotolerance policy regarding UCG, both the AU and ECOWAS also appear to favor diplomatic means over physical intervention, regardless of international opinion. Moreover, as previously mentioned, the Togolese and Mauritanian cases present a similar outcome regarding the results of the subsequent presidential elections, which saw the coup leader being elected. However, this practice is no longer common following the entry into force of the African Charter on Democracy, Elections and Governance in 2012. This new trend is further evidenced by the results of the 2013 presidential elections in Mali which resulted in the election of a third-party.

Finally, in the case of Mali, the Union appeared willing to react to the coup, but in a more complementary capacity to ECOWAS' lead. These disparities raise the question of why these responses are so different from one case to another - and surely, there are internal and external factors which may explain such differences in position -, but they also bring into question the so-called consistency of the AU response and policy towards UCGs. 


\section{Chapter 6: Discussion}

\subsection{Introduction}

This chapter analyzes the African Union's sanctions regime in order to explain a post-2002 shift in African regional activity. It does so in three steps. First, it offers a comparative assessment of the three cases studies (Togo, Mauritania and Mali). This is then followed by a discussion about what such examples reveal regarding the AU's current sanctions regime against UCGs. In this section, attention is given to the evolution of such response since the inception of the organization, as well as to the relationship between the Union and ECOWAS. Finally, this chapter tackles the idea of "good coups" - "or coups against dictatorships that pave the way for democracy" (Derpanopoulos, Frantz \& Wright, 2016, p. 1) - and of the probable role of the AU in that regard, using the particular case of Zimbabwe (2017). Parallels will be drawn between such instances (good coups), the Zimbabwean situation and UCGs more broadly.

\subsection{Analysis}

All three countries in this study present similarities and differences which help paint a more global picture of the AU's stance on, and response to, UCGs. What follows is an examination of both their resemblances and distinctions.

\subsubsection{Togo, Mauritania and Mali: comparing three cases of UCGs in West Africa}

As previously mentioned, the Togolese, Mauritanian and Malian coups all occurred in West Africa following the first meeting of the Peace and Security Council in 2004 and at a time where the African Union sought to adjust its activities to new 
contemporary realities, including new forms of UCGs. The setting in which the coups took place is peculiar in each instance and is thus worth being outlined. In Togo, General Gnassingbé Eyadéma's hold on presidential power was consolidated by both force and political machination "in a career that included military coups, suspicious murders, assassination attempts on opposition leaders, and dramatic appeals to "national unity" at the expense of free expression" ("Gnassingbé Eyadéma Biography," n.d.). He himself had come to power in a 1967 coup, seven years after the country's independence from France. What's more, following the elected succession of his son, Faure Gnassingbé, the UN reported that between 400 and 500 people had been killed in violence around the elections. Since then, Faure's rule has been marked by a poor record in democratic processes, development and human rights, bringing the total ruling time of the Gnassingbé dynasty to over 50 years as of today.

In contrast, Mauritania had suffered several coups since gaining its independence at the end of 1960. In the years prior to the coup, the country had been pressured by international human rights groups to abolish slavery, which remains widespread despite being outlawed. More recently, Mauritania had been the throes of a political crisis, resulting in almost 50 Members of Parliaments quitting the ruling party. At the time of the 2005 coup, the long-serving president, Maaouya Ould Sid'Ahmed Taya, had himself seized power by force more than 20 years prior. The 2008 coup which ensued would see the newly (and only) democratically elected president, Sidi Mohamed Ould Cheikh Abdallahi, deposed by the former chief of his official guard, the same individual would then be elected in the subsequent 2009 elections. 
Similarly, while the Malian conflict appears to be rooted in ethno-regional politics, the March 2012 coup still led to the ousting of the democratically-elected government of Amadou Toumani Touré. Ironically, 2012 would have marked the end of the second term of office of Touré, in accordance with the Malian Constitution which limits individuals to two presidential terms. In addition, Touré had confirmed the year prior that he would not stand for election again. The presidential elections held in July 2013, following the resolution of the coup, saw third-party Ibrahim Boubacar Keïta become president.

Moreover, and interestingly so, all three cases of UCGs, along with the Zimbabwean case tackled later in this chapter, were organized and/or carried out by members of the armed forces, suggesting that the democratic process initiated after the independence did not completely end the practice of military coups on the African continent. Simultaneously, Togo and Mali both saw the incumbent government amend the Constitution in an attempt to legitimate its rule. This appears to confirm the earlier claims of this practice becoming even more likely on the continent, as it has been witnessed in recent years. ${ }^{12}$

In terms of the response, it is important to note that all three countries had ratified the Peace and Security Protocol at the time of the coups, which allowed the African

\footnotetext{
${ }^{12}$ Since the 1990s, at least 30 presidents in sub-Saharan African nations have tried to extend their regimes by tweaking constitutional term limits. Between 2005 and 2015 alone, presidents in Senegal, Burkina Faso, Congo Republic, Congo, Uganda and Rwanda have attempted to extend their terms in office through constitutional or other legal amendments, to name a few.
} 
Union to intervene accordingly, namely by imposing targeted sanctions. In the case of Togo, sanctions were applied by ECOWAS, with support from the AU, in the form of an arms embargo and travel bans. In Mauritania, the Union imposed sanctions through a travel ban and assets freezes. ECOWAS was not involved in the case since Mauritania had withdrawn from the sub-regional organization in 2000. Finally, the Malian case saw the imposition of economic and diplomatic sanctions from ECOWAS, followed by travel bans and assets freezes by the AU. In all cases, suspension from AU activities was introduced.

Additionally, looking at the actors involved in each case reveals that with the exception of Mauritania which was not under the jurisdiction of ECOWAS, both the AU and the sub-regional organization worked together to respond to the UCG, with the former conferring authority and legitimacy to the latter. However, a closer look also reveals some gaps regarding the implementation and coordination of the response. In Togo, while sanctions seemed to have been applied jointly by the AU and ECOWAS, they were not lifted at the same time, thus outlining discrepancies in what each organization considered a satisfying return to democratic and constitutional order. In addition, it was in Mauritania that the AU took the longest to impose sanctions, waiting until the six months suspension period had passed before doing so. In contrast, the Union initiated sanctions quickly in Mali, but ECOWAS followed later, preferring to explore more diplomatic options first. 
Regarding reactions, all three UCGs gave rise to international condemnation of the UCG and support for the AU`s and ECOWAS`s response, namely by the UN, western governments, neighboring countries and, sometimes, the local population. ${ }^{13}$ This was particularly evident in the Mauritanian example where ECOWAS member states played a notable role in resolving the crisis through diplomatic means. In Mali, the conflict saw grater international attention because of its ethno-regional underlining causes, and gave rise to mixed reaction from the international community, but general local support for the junta's actions. On the other hand, both the World Bank and the African Development Bank suspended development aid funds to support ECOWAS and the AU. Apart from this initiative, no other sanctions were imposed by any actors, other than the AU and ECOWAS.

Finally, and as previously discussed, all cases resulted in a return to constitutional order and to the holding of elections, the fairness of which has yet to be confirmed with any certainty. Yet, despite the similar outcome, the Togolese, Mauritanian and Malian cases were all resolved in different timespans, with both the Togo and Malian crises taking less than a month in contrast to the less-than-a-year interval in Mauritania. Lastly, all case studies led to the election of the incumbent leader to power, with the exception of Mali where the military coup leader was promoted to General within the army.

\footnotetext{
${ }^{13}$ Unlike the 2008 coup on which the current dissertation focuses, the 2005 coup in Mauritania gained local support and international sympathy.
} 


\subsubsection{A post-2002 shift in the AU's sanctions regime against UCGs?}

The issue of unconstitutional changes of government is one that poses a serious threat to Africa's development and which has been the focus of this dissertation. Analyzing the current AU's framework on UCGs through the case studies of Togo, Mauritania and Mali includes considering the main actors involved (with emphasis on the AU and ECOWAS), the wide range of provisions and mechanisms that deployed, as well as their incidence on the outcome of the crisis.

The assessment provided in the previous section offers important lessons that are presented below in three encompassing points. The broader discussion of whether or not sanctions are an effective measure is worth exploring but exceeds the scope of this dissertation. The political and socioeconomic factors surrounding the coups are not examined in depth, although it is recognized that they play an important role in the unfolding of the conflicts.

\subsubsection{Unity is strength}

Comparing the three case studies shows that a return to constitutional and democratic rule tends to happen more quickly when the AU and ECOWAS act swiftly and in tandem. The Mauritanian crisis, the only one where no sub-regional organizations were involved, took the longest to be resolved. In contrast, both Togo and Mali saw a resolution to their respective conflicts less than a month after a coup. In those two instances, ECOWAS played an instrumental role in the process, with unwavering support from the Union. However, the cases also reveal some policy practice gaps between the two organizations when it comes to determining whether a country has restored 
constitutional order. In Togo, ECOWAS removed its sanctions in response to Faure Gnassingbé's resignation. On the same day, the PSC introduced its sanctions against the country, which it lifted only after the elections. Likewise, in the case of Mali, not only did the AU suspend Mali from its activities long before ECOWAS, but the sub-regional organization also lifted Mali's suspension sooner, upon the signing of the agreement between ECOWAS and the military junta. This rift between the two organizations shows that in some cases, stepping down for the interim period is deemed sufficient for the subECOWAS, whereas the AU also requires the holding of free and fair elections.

Nevertheless, the case studies show that ECOWAS is closely aligned with the AU's work and that the organization has come to rely increasingly on the sub-regional body when it comes to responding to unconstitutional change of government in the region. This coordination between the Union and the RECs extends beyond the West African region, as will be showcased through the Zimbabwean case, which saw great involvement from the Southern African Development Community.

Overall, it appears that more often than none, both the AU and ECOWAS have managed "to provide effective leadership by coordinating their efforts and sharing responsibilities" (Mkhize, 2013, p. 122). This is mainly due to the sub-regional organization having developed a sanctions policy that allows it to respond to coups effectively (Mkhize, 2013, p. 122). ECOWAS has been characterized by important challenges, including political tensions between French speaking and English speaking member states, and weaknesses in policy and protocol implementation and regional 
integration. However, by being proactive on peace and security issues, the organization is creating a strong example for other regional economic communities within Africa.

\subsubsection{A matter of role-playing}

Another important conclusion drawn from the case studies involved the role of external and internal actors in the conflicts. For one, despite being important donors to the AU and ECOWAS' budgets, international actors do not appear to have had as much weight in the response to the coups and the outcome, with the exception of Mauritania who saw the AU rely heavily on multilateral actors, perhaps for lack of sub-regional jurisdiction.

Still, all three case studies saw a response initiated by either ECOWAS or the Union, which were both central in the resolution of the conflicts. International actors such as the UN, the EU and western governments often responded to the coups, but this was mostly done in support of the regional bodies' first response. In Mali particularly, most actors were simultaneously entangled in other regional dynamics, including fallout from the Libya crisis, unrest in the Sahel zone and security issues facing Nigeria, the region's economic powerhouse. The Malian conflict was also heavily influenced by external forces, with ramifications beyond a single national territory. However, in the context of the coup, these same external actors played a much more minimal role in its resolution. Moreover, it is important to note that in the cases of Mali and Togo, the AU acted relatively on its own terms, using sanctions and other diplomatic means, despite mounting international pressure. This behavior was further communicated with the local 
population in Mali, where the Union quickly condemned the UCG and imposed sanctions, despite general support from the Malian people to the coup.

Lastly, all three instances of UCGs outline the instrumental role military plays in upholding and overthrowing government power. This reveals a lack of clear and definite delineation of spheres of relative autonomy between the civil and the military institutions and significant weaknesses in institutions essential to modern economic and political development (Baynham, 1986).

Regardless of these flaws, the study finds that it is actually the AU, at the regional level and in cooperation with RECs, which has been central in responding to UCGs. Furthermore, the understanding and approach towards unconstitutional changes of government seem to be largely influenced by the AU's strong stance on the matter. Albeit significant structural and technical gaps, the three case studies manage to showcase "the prominent and important role regional organizations have in promoting and spreading norms within the international system" (Girardeau, 2012, p. 92).

\subsubsection{Gaps in the coping mechanisms}

Lastly, the AU and ECOWAS' responses to each UCG generally followed the guidelines prescribed by the Lomé Declaration, which were examined in chapter four of this dissertation. Yet, a thorough analysis of the three case studies reveals important gaps in the AU's response mechanisms to UCGs. 
First, there appears to be no mechanism in place to address incumbent leaders that came into power through unconstitutional means before the establishment of the framework. As previously mentioned, the Lomé Declaration considers four instances as unconstitutional changes of government, the first being a "military coup against a democratically elected government." Out of the three UCG cases presented, two (Togo and Mali) were orchestrated against a government which had itself seized power through a coup, thus an undemocratically-elected leader. Yet in both cases, the AU condemned the UCG and imposed sanctions. This is problematic because it shows poor formulation of the five instances that constitute UCG, affecting the overall credibility of the framework. A similar assessment could be made regarding the Union's warning period before suspending the Member state from its activities. In Togo, the AU waited a little less than a month before suspension, whereas it was almost immediate in Mauritania and Mali. This inconsistency may create confusion, as well as undermine the resolution process and send the wrong message to potential coup perpetrators.

Second, the auto-legitimization of coup leaders through subsequent elections has proven challenging for the AU in terms of implementing the UCG norm. In Togo and Mauritania, electoral endorsement of coups led to the holding of office by those who took unconstitutional action. In Togo specifically, the AU, together with ECOWAS, refused to condone the subsequent election results, despite the violence that followed, perhaps in the interest of political stability in the sub-region. The adoption of the African Charter on Democracy, Elections and Governance in 2007 should have remedied to the matter, but only after 2010, when it became binding. In that regard, the Malian case has shown success in its outcome (the democratic election of a third-party). Yet, the majority of the 
Charter's clauses rely on political commitments rather than formally binding obligations under international law. As such, enforcement remains to be seen (Kane, 2008, p. 44).

A final remark concerns the lack of guidance on the fundamental causes of UCG. Although the examination of these causes remained beyond the scope of this dissertation, it is important to point out that the AU has not developed a "comparable framework for sanctioning major democratic and human rights deficits that [accompany] the emergence of instances of UCG" (Dersso, 2016). In Mali for instance, the coup perpetrated against then-President Amadou Toumani Touré was fueled by frustration over the government's response to separatist Tuareg rebels, Islamist armed groups, and Arab militias who had seized control of northern Mali in April 2012. According to Human Rights Watch, these groups had committed numerous war crimes, including rape, use of child soldiers, attacks on hospitals and schools, abductions and summary executions (Human Rights Watch, 2012).

The African Union Constitutive Act, especially in its Article 4, proclaims the 'respect for democratic principles, human rights, the rule of law and good governance' and 'condemnation and rejection of unconstitutional changes of governments', among its cardinal principles. However, the so-called distinction between UCGs and human rights and democratic deficits prevents the AU from monitoring and responding adequately and comprehensively to coups on the continent.

In many ways, the Zimbabwean case (2017) which will be discussed in the next section illustrates the AU's inability to act coherently when confronted with flagrant human rights abuses or violations of constitutional rule in its member states. 


\subsection{What about "good" coups d'état? The Zimbabwean case}

While the assumption that "all coups fit within the traditional, anti-democratic model" (Varol, 2012, p. 294) has been predominant in the literature, recent scholarship has sought to challenge this conventional intellectual framework by looking at coups which are distinctly more democracy-promoting (Varol, 2012, p. 294). This dissertation attempts to do the same.

In this section, the idea of "good coups" that protect against other threats to democracy is tackled, using the particular case of Zimbabwe (2017). In addition to raising the question of whether coups may actually facilitate transition to democracy, the situation in Zimbabwe highlights some of the complexities of defining what constitutes a UCG today. It is an interesting case to look at in the context of this study because it presents all of the characteristics revealed in the current chapter: a joint effort between the $\mathrm{AU}$ and the sub-regional organization; actor dynamics between the AU, international actors, the local population and the military; and significant gaps in the Union's framework on UCG. Zimbabwe also dresses a more comprehensive picture of the AU's response to UCG by looking beyond the West African region and offers insight in formulating relevant recommendations for improving the framework continent-wide.

First, the political context leading to the coup is laid out. Then, the circumstances surrounding the coup are examined, along with the AU response to it. Notably, explanations are given as to why the ousting of then-President Robert Mugabe was considered to be desirable. Finally, remarks are made regarding the current AU stance on "good" coups, with potential recommendations put forward. 


\subsubsection{Context}

Robert Mugabe assumed control of Zimbabwe in February 1980, following British-supervised parliamentary elections. An icon of pan-Africa nationalism and acclaimed freedom fighter, he would soon start to exhibit signs of dictatorship, corruption and sleaze.

For most of his time in office, Mugabe and the ruling Zimbabwe African National Union-Patriotic Front (ZANU-PF) elite had been accused of high-level graft and embezzlement, as well as being criticized for the political repression, chronic poverty, high unemployment and weak education and healthcare systems in the country. The population had also grown increasingly restless of the extravagant lifestyle of the president's unpopular second wife, Grace, who was expected to succeed the then-93 years old. Grace Mugabe was heading a faction of ZANU-PF veterans known as the G40, and the women's wing, in addition to drawing significant support from the ruling party's loyalist Youth League (Pigou, 2017).

On November 6, 2017, President Mugabe fired his Vice-President, Emmerson Mnangagwa, and expelled him from ZANU-PF on the declared grounds of displaying disloyalty to him. Mnangagwa had been aligned with the military and Zimbabwe's National Liberation War Veterans Association and had had ambitions to succeed as country's leader (Pigou, 2017). 


\subsubsection{Coup}

Late in the night of November 14, the country's security services detained Zimbabwe's President, putting him under house arrest, in what appeared to be a military coup (Feldstein, 2017).

Prior to the coup, a public statement was made by General Constantino Chiwenga, Commander of the Zimbabwean Defense Forces, in which he condemned the current unrest climate in the nation created by the "counter-revolutionary infiltrators" within the ruling ZANU-PF. He also stated that failure from Mugabe to take appropriate measures would warrant military intervention.

Shortly after the arrest of Mugabe, Major General Sibusiso Moyo issued another statement vowing to bring Mugabe and his entourage to justice, while warning other security forces not to intervene. Simultaneously, Major Moyo declared that the move was "not a military takeover of the government" and that the intent was "to pacify a degenerating political, social and economic situation in [the] country which if not addressed may result in violent conflict" (eNCA, 2017).

Three days later, tens of thousands of Zimbabweans took to the streets in Harare to call for the resignation of Mugabe. The following day, members of the ZANU-PF Central Committee held a meeting in which they removed the then-President as their leader, appointing Mnangagwa to replace him. Moreover, the Committee called for the resignation of Mugabe from presidency, threatening to impeach him should he refuse to oblige (Rutherford, 2018, p. 2). 
On Tuesday November 21, Mugabe resigned as president, after originally failing to do so in a live televised broadcast. Three days later, recently returned Mnangagwa was inaugurated as President of Zimbabwe (Rutherford, 2018, p. 2).

\subsubsection{Response}

The case of Zimbabwe is a peculiar one. While there was indeed a military takeover, the army did not, however, declare "martial law, the suspension of the constitution, or the deposition of the country's head of state" (Pigou, 2017), as it has traditionally been the case. Yet, General Chiwenga's statement resembles that of a threat to seize power. As such, the public resignation of then-President Robert Mugabe possesses in fact the hallmarks of a disguised military coup (Pigou, 2017).

Yet, when news broke of the military intervention, there was a strong desire within the Zimbabwean population for the AU and SADC to not get involved. Coincidently, the African Union, along with the Southern African Development Community (SADC), the regional economic community involved in the region, did not expressly condemned the Zimbabwe's military intervention, nor did they immediately describe it as a coup. In a statement made on November 15, AU Commission chairperson Moussa Faki Mahamat urged stakeholders to address the situation in accordance with the country's constitution (AU Commission, 2017).

Then, shortly after and in stark contrast to Mahamat's previous statement, rotating chairperson Guinean President Alpha Condé declared that the crisis in Zimbabwe "[seemed] like a coup" and that the AU would "never accept a military coup d'état", 
before calling for "the respect of the constitution and [for] a return to constitutional rule" (AU Commission, 2017).

Ultimately, the month after Mugabe's resignation, AU Commissioner for peace and security Smail Chergui stated that the leadership transition in Zimbabwe was not a military coup, and that there were therefore no grounds for the organization to impose sanctions against the country. He explained that there was no bloodshed in Zimbabwe ${ }^{14}$, and that the former president had been allowed to step down with "honour" (Muperi \& UK Bureau, 2017).

\subsubsection{Remarks}

Given the circumstances surrounding the situation, the AU's initial careful position is no surprise. Within the African Union, Mugabe had always drawn applause as one of Africa's oldest statesman and revolutionary voice. He was held in high regards by many African leaders, and had remained deeply involved with the AU, serving as chair of the organization in 2015-2016. However, after years of turning a blind eye to President Robert Mugabe's subversion of democracy, the organization was now faced with a coup supported regionally and domestically and which had the potential to facilitate a political transition in Zimbabwe. Yet simultaneously, there was some ambiguity regarding the

\footnotetext{
${ }^{14}$ Following the coup, Mugabe was seen in pictures smiling while meeting with the Generals who had reportedly placed him under house arrest. He also met envoys dispatched by South African counterpart Jacob Zuma and officiated at a university graduation ceremony. Throughout the episode, Mugabe insisted that his authority was never under threat.
} 
nature of the military intervention, especially since the army had made sure not to seize power directly.

The Union was thus facing a choice: condemn the coup and be seen (once again) to protect Mugabe from his political reckoning; or accept the military intervention and potentially end Mugabe's dictatorial reign, though at the risk of legitimating the use of force in politics.

This thesis argues that the AU's response to the Zimbabwean conflict was wrong on many regards. For one, the organization failed to provide a coherent response throughout the episode. By offering two contradicting accounts and ultimately failing to recognize the military intervention as a coup, the AU missed the opportunity to expand its definition of UCG beyond the sole removal of an incumbent leader by force, namely by including the use of force to coerce elected leaders to relinquish power. Additionally, the Zimbabwean case reveals the imbalance of the African Union's framework, which fails to condemn as vigilantly incumbent subversions of democracy, despite rules now prohibiting such transgressions (Roessler \& Abi-Falah, 2017). It becomes challenging, however, to apply said provision to the Zimbabwean situation, given that the country had by then stopped functioning like a democracy, and that Mugabe's rule had been characterized with frequent human rights violations. In that sense, the fault would lie less in the implementation than in the framework itself.

The democratic credentials of those pursuing this course of action (that is, the country's security forces) are also in doubt, given that they had never publicly yearned for democracy - not even after Mugabe lost the presidential election in 2008 - but clung to power regardless. If anything, the Zimbabwean case shows, once more, that coups are 
more often than not, the military's way of protecting its own interests. Such was the case in all three case studies examined in this dissertation. In Togo, armed forces led the coup because of its allegiance to the unconstitutional government; while in both Mauritania and Mali, they perpetrated it as retaliation for a particular event (the sacking of an army official for the former and frustration over a lack of support in the Northern region for the latter).

Most importantly, the Zimbabwean case outlines some of the contradictions characterizing the AU's framework on UCG, especially when it comes to addressing "good coups d'état". Recent scholarship finds that while "democratization coups" have become more frequent worldwide, their most common outcome is to replace the incumbent dictatorship with a "different group of autocrats." The 2011 removal of tyrannical presidents Hosni Mubarak and Mohammed Morsi, and installation of military General Abdel al-Sisi is one of many examples. A similar outcome is currently being seen in Zimbabwe, where the government that replaced Robert Mugabe continues to use heavy-handed measures to squash dissent. The lack of precedent around a leadership transition, coupled with Zimbabwe's weak institutions and fragmented leadership structures, are also to blame (Gopaldas, 2017).

Perhaps a better approach would have been to condemn the coup, and trigger the mechanisms in place (e.g., suspension of AU activities, warning of sanctions imposition and deployment of mediation tools to resolve the conflict) until the release of Mugabe by the military and the installation of a transitional post-Mugabe government. Such response would have strengthened the AU's framework on UCG and sent a clear message to African leaders and potential usurpers, in addition to providing a similar outcome (i.e. the 
removal of Mugabe from power). This would have been done in tandem with SADC in order to ensure effective implementation and monitoring.

In the end, the Zimbabwean army's intentions may have drawn sympathy from regional and local actors, and even from the international community. However, the AU's handling of the case "sets dangerous anti-democratic precedent with major implications" (Pigou, 2017) for the continent. Such stance threatens to undermine the significant gains made in the region to move beyond military-infused politics in order to build a sustainable culture of peace and political stability in Africa.

\subsection{Conclusion}

This chapter has examined a potential post-2002 shift in the African Union's sanctions regime through analysis of the dissertation's three case studies: Togo (2005), Mauritania (2008) and Mali (2012). As a background, the chapter offered a comparative assessment of the cases by outlining their similarities and differences. A discussion then followed which uncovered new realities in the organization's current way of dealing with UCGs on the continent.

First, the response of the AU to the coups revealed that the organization has come to rely increasingly on ECOWAS and that, albeit some gaps in their coordination, the two entities have proven to be successful in facilitating a prompt return to democratic and constitutional order. Secondly, both the Union and the sub-regional body have shown notable autonomy in their response to $\mathrm{UCG}$, despite the international and domestic pressure often put on them. Yet, the prominent influence of the military in upholding and overthrowing government power remains an underlining issue which showcases the 
persisting trend of military interventions in African politics. Thirdly, gaps in the AU's enforcement mechanisms prevent progress in implementing the UCG norm. Such gaps include the lack of mechanism in place to address in incumbent leaders that came into power before the establishment of the framework and the auto-legitimization of coup leaders through subsequent elections. The AU has also failed to develop a comprehensive framework which would involve the imposition of sanctions against major democratic and human rights deficits that underline the emergence of instances of UCG.

Finally, this chapter tackled the idea of "good coups" through the case of Zimbabwe (2017). Once more, the situation illustrated the weaknesses of the AU's governance instruments and the loopholes in its current framework. It was argued that not adopting a consistent approach with regards to coups, regardless of their so-called nature, brings into question the credibility and coherence of the Union's zero-tolerance policy on UCG. With research suggesting that countries that have had coups are more likely to experience subsequent coups - a phenomenon known as the "coup traps" (Tudor, 2017) , or to result in more unrest than prior to the coup, it is questionable whether the chance for democratization is worth the bigger possibility of social chaos, instability and civil war. 


\section{Chapter 7: Conclusion}

This dissertation examined the African Union's sanctions regime against unconstitutional changes of government to answer the following question: what are the implications of the AU's current sanctions regime regarding UCG? This assessment was done through a comparative analysis of three case studies in West Africa: Togo, Mauritania and Mali. An assessment of the cases revealed important trends and patterns in the organization's current response to coups in the region, notably with regards to its increasing reliance and cooperation with sub-regional bodies (in this case, ECOWAS), as well as its relative decisional autonomy from international actors. However, the instrumental role played by the army and persistent military nature of UCGs were also showcased, despite a decreasing rate of such coups on the continent. The AU response to the case studies also sheds light on significant existing gaps in the organization's enforcement mechanisms, namely the subsequent legitimization of coup perpetrators through subsequent elections and/or popular uprisings.

In many aspects, the norm against UCG of the African Union is a significant departure from its predecessor, the OAU, and reflects a new thinking in African politics in the 21 st century. Despite its flaws, the organization has shown a pro-active and innovative approach to dealing with problems that exist in Africa, including unconstitutional changes of government.

This dissertation argues that the Union's response to UCGs should be consistent and uncompromising. In practice, however, decisions made on whether and how to respond often involve matters of principle such as observance of people's and human 
rights, democratic deficits, rule of law and constitutionalism, and have often made the AU response quite contradictory. The 2011 Arab Spring, as well as the case of Zimbabwe (2017) discussed in this dissertation, are appropriate depictions of such inconsistency. In 2011, an unexpected wave of popular protests broke in the Africa's northern shore. Known as the Arab Spring, "the series of demonstrations shook the grip of autocratic regimes across the Arab world, ultimately leading to the fall of Ben Ali of Tunisia, Hosni Mubarak of Egypt, and Muammar Gaddafi of Tunisia” (Pwayidi, 2015, p. 1).

In both cases (the Arab Spring and Zimbabwe), the PSC of the AU expressed (either explicitly or tacitly) its support of the army's and population's attempt to remove their head of state form power in the name of democracy, good governance and respect of human rights. If anything, these examples highlight the AU's failure to clearly define its actions and measures in cases of breaches of democratic and human rights norms. Following the events of the Arab Spring, the PSC acknowledged the weaknesses of its normative framework and recommended an in-depth review of all AU instruments pertaining to UCGs, but nothing concrete followed. As the AU continues to struggle to categorize specific events (e.g. popular uprisings, human rights abuses, manipulation of constitutional term limits) as UCG, its response to UCG remains reactive, incomprehensive and dubious at times.

Despite these significant gaps, the norm against UCGs remains a well-established principle and practice of the African Union. As previously mentioned, its establishment has marked a welcome departure from the organization's predecessor. In addition, analysis of the case studies show that the framework has proven successful on many 
occasions in restoring constitutional and democratic order, while highlighting the Union's central role in that regard, along with ECOWAS. Not without faults, targeted sanctions are the furthest reaching measures in the AU framework and the organization has been able to develop and improve the legal instruments monitoring their implementation. As the most important actor in the promotion of peace and security on the continent, and given its modest debut, the organization and its evolving normative regime hold a lot of hope for the future of Africa.

\subsection{Recommendations}

The conclusion reached in this study is that the AU norm against UCG holds a lot of promise for Africa's peace and security. However, in order to achieve that, the Union will need to revise the legal and institutional framework of its response. The following passage offers summarized recommendations on concrete actions to be taken and to be formulated within the 2009 Ezulwini Framework, the more recent and comprehensive framework on the matter:

- The AU's definition of UCG should be reformulated to better reflect current realities. This would involve a reformulation of the five current instances of UCGs, the categorization of specific events, namely popular uprisings, human right abuses and constitutional manipulation of term limits and elections, and the development of a comparable framework to sanction underlining causes of UCG emergence. Enforcement mechanisms in the form of law-making capacity, "be it through the Pan-African Parliament, the Peace and Security Council or the African court system" (Olivier, 2015), should also be installed to ensure 
compliance with legal instruments, such as the Charter on Democracy, Elections and Governance, which prevents coup perpetrators from participating in subsequent elections. The development of a true 'African Union law', as well as the establishment of an AU supranational body, would facilitate member states accountability and accelerate the process of regional integration.

- By taking the lead on peace and security issues, ECOWAS is setting a strong example for other regional economic communities within Africa. Bearing in mind instances of coordination between the AU and ECOWAS, all RECs should develop a peace and security architecture which aligns itself with the AU sanction policy. Moreover, coordination should be showcased when recognizing instances of UCGS, imposing sanctions against unconstitutional leaders and determining whether a country has restored constitutional order. The principle of subsidiary has also proven successful towards this end, with the REC acting first and the AU following shortly after. Moreover, the Pan-African Parliament should seek support and cooperation from national parliaments in implementing sanctions through legislation, and efforts should be made, within the Continental Early Warning System, to strengthen information and communication systems, as well as cooperation efforts, between the AU conflict-preventing bodies and the RECs. Institutional reforms should also be made towards achieving ownership of the Union through required financing from its Member states, in order to avoid fiscal constraints and overdependence on external donors. Finally, a shorter "grace" period for the restoration of constitutional order may be considered since the current six-month window may give enough time for unconstitutional regimes to 
consolidate their position. The cases reviewed in this dissertation resulted in a relatively quick return to democracy, in part because of the swift response of the AU and ECOWAS.

- The African Union should operationalize the planned Court of Justice and Human Rights to prosecute perpetrators of UCGs in member states. The Court should be free from politicization and innovative in its ability to interpret provisions on UCGs. Formal recognition should also be conferred upon private parties whose interests are affected by AU decisions.

- Unfortunately, not much can be done about coups that occurred before the framework was in place. However, the AU can ensure that moving forward, it adopts a truly consistent zero-tolerance policy regarding unconstitutional changes of government, including so-called good coups. Failing to do so would set out a cycle of political instability in the region, as well as foster incredibility towards the Union. Whether or not the organization should provide a more moderate response to "democratic" coups remains to be assessed, however, the African Union should maintain consistency and objectivity when responding to cases of UCG, regardless of the nature or intentions.

- Beyond the sole scope of sanctions, it is important to consider the overall nonWestern strategies used by the AU to address UCG. Such strategies include the AU's African Transitional Justice Framework, "which assists Member States emerging from violent conflicts and regression in their pursuit of accountability, sustainable peace, justice and reconciliation" (Draft AU Transitional Justice Policy Framework, 2015, p. 2) and the Panel of the Wise, often identified as an 
important actor for mediation and political negotiations facilitation. These mechanisms are important because they embrace traditional and alternative justice systems "whose twin objectives of ensuring accountability and reconciliation is the hallmark of African understanding of justice" (Wachira, 2017, p. 20). The restorative, redistributive and transformative nature of these systems should thus be favored and reflected in the overall AU Framework against UCGs, to the same extent as the sanctions regime itself. 


\section{Appendices}

\section{Appendix A}

\section{A.1 Number of Military Coups (successful and attempted per Sub-region)}

\begin{tabular}{|l|l|l|l|}
\hline & $\mathbf{1 9 6 0 - 1 9 6 9}$ & $\mathbf{1 9 7 0 - 1 9 8 9}$ & $\mathbf{1 9 9 0 - 2 0 1 0}$ \\
\hline West Africa & 19 & 49 & 36 \\
\hline Central Africa & 8 & 14 & 13 \\
\hline Eastern Africa & 10 & 26 & 12 \\
\hline Southern Africa & 0 & 10 & 6 \\
\hline TOTAL & 37 & 99 & 67 \\
\hline
\end{tabular}

Source: Barka, H. B., \& Ncube, M. (2012). Political Fragility in Africa: Are Military Coups d'Etat a Never-Ending Phenomenon?, African Development Bank (September 2012) 


\section{References}

African Charter on Democracy, Elections and Governance, adopted by The Eighth Ordinary Session of The Assembly, held In Addis Ababa, Ethiopia on 30th January 2007.

African Union (Assembly of Heads of State and Government) 'Decision on the Location of the Headquarters of AU institutions in various AU Regions of the Continent' (Abuja 2005) Assembly/AU/Dec.64 (IV).

African Union (Assembly of Heads of State and Government) 'Decision on the Seats of the African Union' (Addis Ababa 2004) AU/Dec.45 (III)

African Union (Assembly of Heads of State and Government) 'Decision on the Merger of the African Court on Human and Peoples' Rights and the Court of Justice of the African Union' (Sirte 2005) Assembly/AU.Dec.83 (V).

African Union (Assembly of Heads of State and Government) 'Decision on the establishment of the Peace and Security Council of the African Union' (Durban 2002) Ass/AU/Dec.3(I)

African Union (Assembly of Heads of State and Government). Decision on the Prevention of Unconstitutional Changes of Government and Strengthening the Capacity of the African Union to Manage Such Situations, Doc. Assembly/AU/4(XVI).

African Union (Assembly of Heads of State and Government). Decision on the Resurgence of the Scourge of Coups d'État in Africa, Assembly/AU/Dec.220(XII

African Union (Assembly of Heads of State and Government) 'Solemn Declaration on a Common African Defense and Security Policy' (Sirte 2004), Art. 26 and 27.

African Union (Assembly of Heads of State and Government) 'Statute of the Economic, Social and Cultural Council of the African Union' (Addis Ababa 2004) AU/Dec.48 (III) 
African Union. Background Paper on Implementing the Kigali Decision on Financing the Union. September 2016.

African Union Commission Peace and Security Department. 2018. Panel of the Wise (PoW) [Online]. Available at: http://www.peaceau.org/en/page/29-panel-of-the-wise-pow.

African Union (Commission). 'Statement by the Chairperson of the African Union Commission on the situation in Zimbabwe', 15 November 2017.

African Union. Draft Transitional Justice Policy Framework, 2015.

African Union (Peace and Security Council). Communiqué of the 25th Meeting, 1-4, Doc. No. PSC/PR/Comm. (XXV) (Feb. 25, 2005).

African Union (Peace and Security Council), 'Ezulwini Framework for the Enhancement of the Implementation of Measures of the African Union in Situations of Unconstitutional Changes of Government in Africa', PSC/PR/2(CCXIII)/Assembly/AU3XIV, 17-19 December 2009.

Agbese, P. (2004). Soldiers as rulers: Military performance. The military and politics in Africa, $57-90$.

Alozieuwa, S. H. (2013). The March 22, 2012 Coup in Mali: Lessons and Implications for Democracy in the West Africa Subregion in the Wave of Transnational Terrorism. Democracy and Security, 9(4), 383-397.

Aneme, A. (2010). Introduction to the Norms and Institutions of the African Union. Text and Pictures, Hauser Global Law School Program, 5.

Aniekwe, C. C. (2015). Regional Organisations and the Enforcement of Constitutionalism: Reflections on the Implementation of Chapter 8 of the African Charter on Democracy Elections and Governance (ACDEG). 
Aning, K., \& Edu-Afful, F. (2016). African Agency in R2P: Interventions by African Union and ECOWAS in Mali, Cote d'Ivoire, and Libya. International Studies Review, 18(1), 120133.

Banjo, A. (2008). Constitutional and succession crisis in West Africa: the case of Togo. African Journal of Legal Studies, 2(2), 147-161.

Barka, H. B., \& Ncube, M. (2012). Political Fragility in Africa: Are Military Coups d'Etat a Never-Ending Phenomenon?. African Development Bank (September 2012), 3.

Barracca, S. (2007). Military coups in the post-cold war era: Pakistan, Ecuador and Venezuela. Third World Quarterly, 28(1), 137-154.

Baynham, S. (Ed.). (1986). Military power and politics in black Africa. Routledge.

Boutellis, A., \& Williams, P. D. (2013). Peace operations, the African Union, and the United Nations: Toward more effective partnerships. New York: International Peace Institute.

Boutros-Ghali, B. (1995). Supplement to an Agenda for Peace: position paper of the SecretaryGeneral on the occasion of the fiftieth anniversary of the United Nations. UN.

A Centre for Democracy and Development. Preventing Unconstitutional Changes of Governments in West Africa: The Role of State and Non-State Actors. CDD - UCG Policy Brief.

Charron, A., \& Portela, C. (2015). The UN, regional sanctions and Africa. International Affairs, 91(6), 1369-1385.

Chirisa, I. E., Mumba, A., \& Dirwai, S. O. (2014). A review of the evolution and trajectory of the African union as an instrument of regional integration. SpringerPlus, 3(1), 101.Clark, J. F. (2007). The decline of the African military coup. Journal of Democracy, 18(3), 141155. 
Collier, P. (2008). Let Us Now Praise Coups, Retrieved from http://washingtonpost.com.

Collier, P. 2009. War, Guns, and Votes: democracy in dangerous places. New York, NY: HarperCollins.

Collins, S. D. (2009). Democracy Sanctions An Assessment of Economic Sanctions as an Instrument of Democracy Promotion. Taiwan Journal of Democracy, 5(2).

Communiqué du Conseil des Ministres du jeudi 27 décembre 2018 (2018, December 27), Malijet. Retrieved from http://malijet.com.

Constitutive Act of the African Union, adopted in Lomé, Togo 11 July 2000, entered into force 26 May, 2001.

Cortright, David, and George Lopez, eds. (2002a) Smart Sanctions. New York: Rowman and Littlefield.

Cortright, D., Lopez, G. A., \& Gerber, L. (2002). Sanctions and the search for security: Challenges to UN action. Lynne Rienner Publishers.

Cowell, F. (2011). The impact of the ECOWAS Protocol on Good Governance and Democracy. African Journal of International and Comparative Law, 19(2), 331-342.

Cristiani, D., \& Fabiani, R. (2013). From Disfunctionality to Disaggregation and Back?: The Malian Crisis, Local Players and European Interests. Istituto affari internazionali.

Daoudi, M. S., \& Dajani, M.S. (1983). Economic Sanctions: Ideals and Experience. Routledge Kegan \& Paul.

Declaration, S. (1999). EAHG/Draft. Decl (IV) Rev1, Fourth Extraordinary Session of the African Union Assembly of Heads of State And Government, 8-9.

Declaration on the framework for and OAU response to unconstitutional changes of government, (Lomé Declaration), AHG/Decl.5 (XXXVI), July 10-12, 2000, Lomé, Togo. 
Denzin, N. K. (2005). Introduction: The Discipline and Practice of Qualitative Research. I: NK Denzin \& YS Lincoln (red.), Handbook oI Qualitative Reserach (sid. 1132).

Derpanopoulos, G., Frantz, E., Geddes, B., \& Wright, J. (2016). Are coups good for democracy?. Research \& Politics, 3(1), 2053168016630837.

Dersso, S. (2016). Unconstitutional Changes of Government and Unconstitutional Practices in Africa. African Politics, African Peace: Summary Paper from the Program on African Peace Missions. Paper No. 2.

Desmidt, S. (2016). Peacebuilding, conflict prevention and conflict monitoring in the African Peace and Security Architecture. European Centre for Development Policy Management, $1-16$

Diamond, L., Linz, J., \& Lipset, S. M. (1989). Democracy in Developing Countries, Volume 3: Asia. Boulder, CO: Lynne Rienner.

African Union. Draft Transitional Justice Policy Framework, 2015.

Drezner, D. W. (2011). Sanctions sometimes smart: targeted sanctions in theory and practice. International Studies Review, 13(1), 96-108.

Dube, R. (2010). Fighting unconstitutional changes of government or merely politicking? A critical analysis of the African Union response.

ECOWAS, Protocol A/SP1/12/01 on 'Democracy and Good Governance', supplementary to the protocol relating to the mechanism for conflict prevention, management, resolution, peacekeeping and security (Dakar, Dec. 2001).

Full statement by Zim army on state broadcaster (2017, November 15), eNCA, 15 November. Retrieved from https://www.enca.com. 
Engel, U., \& Porto, J. G. (2009). The African Union's new peace and security architecture: toward an evolving security regime?. African Security, 2(2-3), 82-96.

Farrall, J. M. (2007). United Nations sanctions and the rule of law (Vol. 56). Cambridge University Press.

Fawcett, L. (2004). Exploring regional domains: a comparative history of regionalism. International Affairs, 80(3), 429-446.

Feldstein, S. (2017, November 15). After Coup, Will Zimbabwe See Democracy or Dictatorship?, The Conversation. Retrieved from http://theconversation.com.

Förander, K. (2010). Dealing with unconstitutional changes of government-The African Union Way.

Girardeau, N. A. (2012). UN, AU and SADC approaches to unconstitutional changes of government: the case of Madagascar (Doctoral dissertation, Stellenbosch: Stellenbosch University).

Giumelli, F. (2015). Understanding United Nations targeted sanctions: an empirical analysis. International Affairs, 91(6), 1351-1368.

Gnassingbé Eyadéma Biography (n.d). Retrieved from http://biography.jrank.org.

Gopaldas, R. (2017). Good coup, bad coup? Institute for Security Studies.

Hagberg, S., \& Körling, G. (2012). Socio-political Turmoil in Mali: The Public Debate Following the" Coup d'État" on 22 March 2012. Africa Spectrum, 111-125.

Hufbauer, G. C., Schott, J. J., \& Elliott, K. A. (1990). Economic sanctions reconsidered: History and current policy (Vol. 1). Peterson Institute.

Hufbauer, G. C., Schott, J. J., Elliott, K. A., \& Oegg, B. (2007). Economic Sanctions Reconsidered, (Washington, DC: Peterson Institute for International Economics). 
Hawkins, D., \& Lloyd, J. (2003). Questioning comprehensive sanctions: the birth of a norm. Journal of human rights, 2(3), 441-454.

Hoeffler, A. (2005). Coup traps: why does Africa have so many coups d'état?.

Hofmann, S. (2016). Targeted Sanctions: The Impacts and Effectiveness of United Nations Action.

Houngnikpo, M. C. (2016). Guarding the Guardians: civil-military relations and democratic governance in Africa. Routledge.

Hovi, J., Huseby, R., \& Sprinz, D. F. (2005). When do (imposed) economic sanctions work?. World Politics, 57(4), 479-499.

Human Rights Watch. (2012, April 30). Mali: War Crimes by Northern Rebels Armed Groups Commit Rape, Use Child Soldiers. Retrieved from https://www.hrw.org.

Huntington, S. P. (Ed.). (1962). Changing patterns of military politics (Vol. 3). Free Press.

Ikome, F. N. (2007). Institute for global dialogue.

Lobakeng, R. (2017). African Solutions to African problems: a Viable Solution towards a United, Prosperous and Peaceful Africa?.

Kane, I. (2008). The implementation of the African charter on democracy, elections and governance. African Security Studies, 17(4), p. 44.

Jeong, J. M. (2018). Do sanction types affect the duration of economic sanctions? The case of foreign aid. International Political Science Review, 0192512117753150.

Johnson, T. H., Slater, R. O., \& McGowan, P. (1983). Explaining African military coups d'etat, 1960-1982. American Political Science Review, 78(3), 622-640.

Karock, U. (2014). The African Peace and Security Architecture: Still under construction. Directorate-General for External Policies of the European Union. 
Kieh, G. K., \& Agbese, P. O. (Eds.). (2004). The military and politics in Africa: from engagement to democratic and Constitutional control. Ashgate Publishing, Ltd.

Kufuor, K. O. (2005). THE COLLAPSE OF THE ORGANIZATION OF AFRICAN UNITY: LESSONS FROM ECONOMICS, AND HISTORY. Journal of African Law, 49(2), 132144.

Magliveras, K. (2011). The sanctioning system of the African Union: Part success, part failure?. an Institute of Security Studies Expert Roundtable on The African Union: The First Ten Years, Addis Ababa, Ethiopia, 11-13.

Magliveras, K. D., \& Naldi, G. J. (2002). The African Union-A New Dawn for Africa?. International \& Comparative Law Quarterly, 51(2), 415-425.

Magliveras, K. D., \& Naldi, G. J. (2006). The African Court of Justice. ZaöRV, 66, 192.

Malabo Protoocl on the Amendments to the Protocol creating the African Court of Justice and Human Rights, Malabo, Equitorial Guinea, 27 June 2014, entered into force 29 January 2018.

Manirakiza, P. (2016). Insecurity implications of unconstitutional changes of government in Africa: from military to constitutional coups. Journal of Military and Strategic Studies, 17(2).

Marvasti, A. (2003). Qualitative research in sociology. Sage.

Masters, J. (2015). What Are Economic Sanctions?. Council for Foreign Relations.

Matthews, K. 2008. Renaissance of Pan-Africanism: The AU and the New Pan-Africanist. In Akopari, J., Ndinga-Mvumba, A. and Muruthi, T. (eds.). The African Union and its Institutions. Auckland Park: Jacana Media, pp. 25-41. 
McGowan, P. J. (2003). African military coups d'état, 1956-2001: frequency, trends and distribution. The Journal of Modern African Studies, 41(3), 339-370.

McGowan, P. J. (2005). Coups and conflict in West Africa, 1955-2004: Part I, theoretical perspectives. Armed Forces \& Society, 32(1), 5-23.

McGowan, P. J. (2005). Coups and conflict in West Africa, 1955-2004: Part II, empirical Findings. Armed Forces \& Society, 32(2), 234-253.

McLafferty, C. J. (2011). Comprehensive Sanctions Vs. Targeted Sanctions: Achieving Goals (Doctoral dissertation, Pennsylvania State University).

McMahon, R. (2006). UN Sanctions: A Mixed Record. Council on Foreign Relations.

Miyandazi, L. 2016. Is the African Union's financial independence a possibility? ECDPM Talking Points blos, 24 August 2016.

Mkhize, S. (2013). Assessing the efficacy of the AU sanctions policies with regard to unconstitutional changes in government: the examples of Guinea and Madagascar (Doctoral dissertation).

Møller, Bjørn. "The African Union as a security actor: African solutions to African problems?." (2009).Mouton, J., \& Babbie, E. (2001). The practice of social research. Cape Town: Wadsworth.

Muperi, W., \& UK Bureau. (2017, December 22). African Union - There Was No Coup in Zimbabwe, but 'Just a Dialogue Between the Leadership of the Country, allAfrica. Retrieved from https://allafrica.com.

Murithi, T. (2008). The African Union's evolving role in peace operations: the African Union Mission in Burundi, the African Union Mission in Sudan and the African Union Mission in Somalia. African Security Studies, 17(1), 69-82. 
Nathan, L. (2013). African solutions to African problems: South Africa's foreign policy.

Nkosi, M. (2013). Analysis of OAU/AU responses to unconstitutional changes of government in Africa (Doctoral dissertation, University of Pretoria).

Nantulya, P. (2016, June 8). The African Union's Panel of the Wise and Conflict Prevention, Africa Center for Strategic Studies. Retrieved from: https://africacenter.org.

Norwegian Embassy to Ethiopia. (2009). Sanctions Committee established. Retrieved from http://www.norway.org.et/News_and_events/au/sanction/.

Noyes, A., \& Yarwood, J. (2013). The AU continental early warning system: from conceptual to operational?. International Peacekeeping, 20(3), 249-262.

OAU (Organisation for African Unity). 1963. "OAU Charter" [Online]. Available at: http://www.adrica-union.org.root/Documents/Treatise/Texts/OAU/Charter1963.

Okyere, F. O., Emmanuel Kwesi Aning, D., \& Abdallah, M. (2012). Addressing Emerging Security Threats in Post-Gaddafi Sahel and ECOWAS Response to the Malian Crises.

Olivier, M. E. (2015). The role of African Union law in integrating Africa. South African Journal of International Affairs, 22(4), 513-533.

Oloruntoba, S. O. (2016). ECOWAS and Regional Integration in West Africa: From State to Emerging Private Authority. History Compass, 14(7), 295-303.

Omorogbe, E. Y. (2011). A Club of Incumbents-The African Union and Coups d'Etat. Vand. J. Transnat'l L., 44, 123.

Onwumechili, C. 1998. African Democratization and Military Coups. Westport, CT. Praeger.

Pape, R. A. (1997). Why economic sanctions do not work. International security, 22(2), 90-136.

Parties Agree on Interim Govt, Election Date (2009, June 4), Le Soleil. Retrieved from http://allafrica.com. 
Peksen, D. (2009) Better or Worse? The Effect of Economic Sanctions on Human Rights. Journal of Peace Research 46 (1): 59-77.

Peksen, D., \& Drury, A. C. (2009). Economic sanctions and political repression. Human Rights Review,10(3), 393-411.

Pigou, P. (2017). Zimbabwe's Very Peculiar Coup.

Presidential Statement, 19 August 2008, S/PRST/2008/30.

Press Release, European Parliament, EU Parliement Says Fresh Elections Needed in Togo (2005, May 12). Retrieved from http://www.delusanyc.ec.europa.eu.

PSC Communiqué, 7 August 2008, PSC/PR/Comm(CLIV).

PSC Communiqué (Minutes), 22 September 2008, PSC/MIN/Comm.2(CLI).

PSC Communiqué, 11 November 2008, PSC/PR/Comm(CLVI).

PSC Communiqué (Minutes), 22 December 2008, PSC/MIN/Comm.3(CLXIII)

PSC/PR/(CLXVIII), 5 February 2009.

Protocol on relations between the African Union and the Regional Economic Communities, Ninth Ordinary Council, 1-3 July 2007, Accra, Ghana.

Protocol Relating to the Establishment of the Peace and Security Council of the African Union, Durban, South Africa, 10 July 2002, entered into force 26 December 2003.

Protocol on the Statute of the African Court of Justice and Human Rights, Adopted by the Eleventh Ordinary Session of the Assembly, held in Sharm El-Sheikh, Egypt, 1st July 2008.

Pwayidi, D. A. (2015). An Assessment of the Au's Management of the North African Crises (Arab Spring)(Doctoral dissertation, University of Ghana).

Renner, M. (2002). The anatomy of resource wars. Worldwatch paper, 16, 2. 
Mali forms new caretaker government (2012, August 20), Reuters. Retrieved from http://www.reuters.com.

Roessler, P., \& Abi-Falah, L. (2017). Blurry Lines: The African Union's Imbalanced Regime of Constitutionalism and Its Consequences.

Rutherford, B. (2018). Mugabe's shadow: limning the penumbrae of post-coup Zimbabwe. Canadian Journal of African Studies/Revue canadienne des études africaines, $1-16$.

Sithole, T. (2018). A Review of the African Union framework and mechanism on political peace and security. Journal of African Union Studies, 7(1), 67-90.

Souaré, I. K. (2009). The AU and the challenge of unconstitutional changes of government in Africa. Institute for Security Studies Papers, 2009(197), 16-16.

Statute of the Commission of the African Union, First Ordinary Session, 9 - 10 July 2002, Durban, South Africa.

Tudor, M. (2017, November 24). Can a coup in Zimbabwe really usher in democracy?, NewStatesmanAmerica. Retrieved from https://www.newstatesman.com.

Wallensteen, P., Strandow, D., \& Holtom, P. (2007). United Nations arms embargoes: their impact on arms flows and target behaviour.

Sturman, K., \& Hayatou, A. (2010). The Peace and Security Council of the African Union: from design to reality.

Tostensen, A., \& Bull, B. (2002). Are Smart Sanctions Feasible? World Politics 54 (3), 373-403.

Trachsler, D. (2010). Economic Sanctions: Silver Bullet or Harmless Dud?. CSS analysis in security policy, 83(83). 
UNSC (2013). Report of the United Nations Secretary-General on the situation in Mali, 10 June 2013, S/R/2013/338, 14.

Varol, O. O. (2012). The democratic coup d'état. Harv. Int'l LJ, 53, 291.

Viljoen, F. (2012). International human rights law in Africa. Oxford University Press on Demand.

Vines, A. (2013), A decade of African Peace and Security Architecture. International Affairs, 89: 89-109. doi: 10.1111/1468-2346.12006.

Wachira, G. (2017). The African Union Transitional Justice Policy Framework: Promise and Prospects.

Wagner, Daniel. (2015, May 4). Do Sanctions Work?, HUFFINGTON POST. Retrieved from https://www.huffingtonpost.com.

Weiss, T. G., \& Welz, M. (2014). The UN and the African Union in Mali and beyond: a shotgun wedding?. International Affairs, 90(4), 889-905.

Wiking, S. (1983). Military Coups in Sub-Saharan Africa: how to justify illegal assumptions of power. Nordiska Afrikainstitutet.

Williams, P. D. (2007). From non-intervention to non-indifference: the origins and development of the African Union's security culture. African Affairs, 106(423), 253-279.

Williams, P. D. (2009). The Peace and Security Council of the African Union: evaluating an embryonic international institution. The Journal of Modern African Studies, 47(4), 603626.

Zamfir, I. (2016). Africa's Economic Growth: Taking Off Or Slowing Down?. Members' Research Service, Directorate-General for Parliamentary Research Services, European Parliament. 